HIAS-E-73

\title{
Transfer Pricing and the Arm's Length Principle under Imperfect Competition
}

\author{
Jay Pil Choi ${ }^{(a),(b)}$, Taiji Furusawa ${ }^{(c)}$ and Jota $\operatorname{Ishikawa}^{(d),(e)}$ \\ (a) Department of Economics, Michigan State University \\ (b) Hitotsubashi Institute for Advanced Study, Hitotsubashi University \\ (c) Faculty of Economics, University of Tokyo \\ (d) Faculty of Economics, Hitotsubashi University
}

(e) RIETI

October, 2018

Advanced Study

Hitotsubashi Institute for Advanced Study, Hitotsubashi University

2-1, Naka, Kunitachi, Tokyo 186-8601, Japan

tel:+81 425808604 http://hias.ad.hit-u.ac.jp/

HIAS discussion papers can be downloaded without charge from:

http://hdl.handle.net/10086/27202

https://ideas.repec.org/s/hit/hiasdp.html

All rights reserved. 


\title{
Transfer Pricing and the Arm's Length Principle under Imperfect Competition*
}

\author{
Jay Pil Choi ${ }^{\dagger}$
}

\author{
Taiji Furusawa
}

October 2, 2018

\author{
Jota Ishikawa ${ }^{\S}$
}

\begin{abstract}
This paper analyzes incentives of a multinational enterprise to manipulate an internal transfer price to take advantage of corporate-tax differences across countries under both monopoly and oligopoly. We examine "cost plus" and "comparable uncontrollable price" as two alternative implementations of the so-called arm's length principle (ALP) to mitigate this problem. Tax-induced foreign direct investment (FDI) may entail inefficient internal production. We show how the mechanisms behind such inefficient FDI differ between alternative implementation schemes of the ALP and explore implications of the ALP for welfare and dual sourcing incentives. We also develop a novel theory of vertical foreclosure as an equilibrium outcome of strategic transfer pricing.
\end{abstract}

JEL Codes: F12, F23, H26, L12, L13, L51, L52

Key Words: Foreign Direct Investment; Multinational Enterprise; Corporate tax; Transfer Pricing; Arm's Length Principle; Vertical Foreclosure

${ }^{*}$ We thank Hayato Kato, Yuka Ohno, Pascalis Raimondos, Martin Richardson, Jay Wilson and participants in various conferences and seminars for valuable discussions and comments. This research was initiated during Choi's visit to Hitotsubashi Institute for Advanced Study whose hospitality is greatly appreciated. Choi acknowledges financial support from the Ministry of Education of the Republic of Korea and the National Research Foundation of Korea: Grant Number NRF-2016S1A5A2A01022389. Furusawa and Ishikawa acknowledge financial support from the Japan Society of the Promotion of Science through the Grant-in-Aid for Scientific Research (S): Grand Number 26220503 and (A): Grant Number 17H00986.

${ }^{\dagger}$ Department of Economics, Michigan State University and Hitotsubashi Institute for Advanced Study, Hitotsubashi University; E-mail: choijay@msu.edu

${ }^{\ddagger}$ Faculty of Economics, University of Tokyo; E-mail: furusawa@e.u-tokyo.ac.jp

$\S$ Faculty of Economics, Hitotsubashi University \& RIETI; E-mail: jota@econ.hit-u.ac.jp 


\section{Introduction}

There exist differences in corporate tax rates and preferential tax measures among countries. ${ }^{1}$ Since multinational enterprises (MNEs) are actively engaged in intrafirm transactions across boarders, ${ }^{2}$ they have incentive to manipulate internal transfer prices to reduce their tax obligations, which is called "transfer pricing". It has been well documented that MNEs shift their profits from high-tax countries to low-tax jurisdictions (see Hines and Rice, 1994; Huizinga and Laeven, 2008; Bauer and Langenmayr, 2013). For instance, inspections by the Vietnamese tax authorities found that "the most common trick played by FDI enterprises to evade taxes was hiking up prices of input materials and lowering export prices to make losses or reduce profits in books." ${ }^{3}$ In addition, Egger et al. (2010) find that an average subsidiary of an MNE pays about $32 \%$ less tax than similar local firms in high-tax countries. According to Goldman Sachs, tax saving by US MNEs is 2 trillion dollars which are equivalent to 4 years' worth of US corporate tax revenues (Nikkei, August 31, 2016).

If governments overlook internal exchanges within the firm, MNEs may shift all profits to low-tax or no-tax jurisdictions via transfer pricing. Governments thus impose transfer pricing rules to control tax manipulation. The Organisation for Economic Co-operation and Development (OECD) published the guidelines for transfer pricing in 1995, which were reformed in $2010{ }^{4}$ The OECD proposed that internal transfer prices follow the so-called "Arm's Length Principle (ALP)".

The basic approach of the ALP is that the members of an MNE group should be treated "as operating as separate entities rather than as inseparable parts of a single unified business" and the controlled internal transfer price should mimic the market price that would be obtained in comparable uncontrolled transactions at arm's length. This kind of "comparability analysis" is at the heart of the application of the ALP. The 2010 OECD Transfer Pricing Guidelines for Multinational Enterprises and Tax Administrations 2010 states that the "comparable uncontrolled price" (hereafter, CUP) method:

\footnotetext{
${ }^{1}$ Preferential tax measures are observed in many countries. For example, Vietnam grants special or preferential tax rates to attract foreign direct investment (FDI). Thailand provides tax incentives for FDI. The Taiwanese corporate tax rate is lower by 7 percentage points for foreign firms with a fixed place of business or a business agent in Taiwan.

${ }^{2}$ Bernard et al. (2010) report that over $46 \%$ of U.S. imports composed of intrafirm transactions in 2000.

${ }^{3}$ http://vietnamlawmagazine.vn/transfer-pricing-unbridled-at-fdi-enterprises-4608.html

${ }^{4}$ The OECD also initiated a project called "Base Erosion and Profit Shifting" in 2012 and created the action plan to address base erosion and profit shifting.
} 
"compares the price charged for property or services transferred in a controlled transaction to the price charged for property or services transferred in a comparable uncontrolled transaction in comparable circumstances. If there is any difference between the two prices, this may indicate that the conditions of the commercial and financial relations of the associated enterprises are not arm's length, and that the price in the uncontrolled transaction may need to be substituted for the price in the controlled transaction." (p. 63)

Currently, the ALP is the international transfer pricing principle to which OECD member countries have agreed should be used for tax purposes by MNE groups and tax administrations. Thus, it is important to explore incentives of MNEs for transfer pricing to take advantage of tax differences across countries and implications of the ALP as countermeasures against profit shifting in various market structure scenarios.

This paper specifically investigates transfer pricing resulting from tax-induced FDI and the effects of the ALP when imperfect competition prevails in the final-good market. To this end, we consider a very stylized simple set-up of two countries with different corporate tax rates. We first analyze a setting in which a monopolist produces and sells a final product in country $H$ (Home) with a higher corporate tax rate, whereas it sources its intermediate input from country $F$ (Foreign) with a lower corporate tax rate. This could be the case if the input is a labor-intensive good and the wage rate is much lower in Foreign. Alternatively, the input is a natural resource that is available only in Foreign. We specifically consider two channels for the monopolist to source the input. It can be outsourced from independent firms in Foreign, or can be produced internally by the foreign subsidiary established through FDI. In the presence of FDI, the monopolist becomes an MNE.

Not surprisingly, FDI can be used even if it is less efficient to produce the input internally, because it can be used as a vehicle to lessen its tax burden with an inflated internal price. Interestingly, however, such FDI benefits consumers, because tax manipulation by the monopolist leads to more production which alleviates allocative inefficiency due to the market power.

We examine the effects of the ALP introduced in the presence of transfer pricing. As the CUP method is the most direct and reliable, it is the preferred method when applying the ALP. In practice, however, it may be difficult to find a transaction between independent enterprises that is similar enough. This would be particularly so in the monopoly context where the required input is demanded only by the monopolist and 
there is no comparable input market available. In such a case, there are other methods suggested as the ALP. ${ }^{5}$

In our theoretical set-up, we examine the "cost plus" (hereafter, CP) method, because the CP method as well as the CUP method are traditional transaction methods. The $\mathrm{CP}$ method mandates that the transfer price should reflect the production cost of the internally-transacted input. However, the true production cost is typically non-observable by tax authorities and hard to ascertain. As a result, it can be manipulated at certain costs. Following the existing literature, we introduce "concealment costs" to analyze the incentive to engage in FDI and the determination of the internal price when the $\mathrm{CP}$ method is used due to the absence of comparable transactions in the market. More specifically, when an MNE's internal price deviates from its true marginal cost (MC) in the presence of the CP method, there are some costs to avoid such institutional constraints on the internal transfer price. These costs may be literally concealment costs to keep two separate books or may reflect expected punishment for the deviation as in Allingham and Sandmo (1972) and Kant (1988).

The MNE thus trades off potential tax benefits against concealment costs when determining the optimal transfer price. In particular, we show that the optimal transfer price is equivalent to the minimization of what we call "perceived marginal cost (PMC)". This characterization provides a very simple condition for the optimality of FDI vis-a-vis outsourcing if the concealment costs are linear in the quantity of internally-transferred inputs. In addition, we show that if the ALP is introduced in the presence of transfer pricing, profit shifting is obviously mitigated but consumers as well as the monopolist get hurt. As a result, social welfare may deteriorate.

If the concealment costs are convex instead, there may be incentives for the MNE to engage in dual sourcing, that is, a part of the required input is produced from the foreign subsidiary whereas the rest is outsourced. As a result, a dual sourcing strategy may provide the tax authority with the ability to identify a comparable market price and adopt the CUP method as an application of the ALP. In such a situation, we demonstrate that the imposition of the CUP method with dual sourcing leads to unintended consequences and detrimental effects if it switches the MNE's sourcing decision from the dual sourcing to the internal sourcing alone in order to avoid the application of the CUP method.

We also analyze import tariffs as countermeasures against the potential tax shifting.

\footnotetext{
${ }^{5}$ Other suggested methods include the cost plus method, the resale price method, the transactional net margin method, and the transactional profit split method. See OECD (2010) for more details.
} 
An import tariff can completely offset the incentive to engage in inflated transfer price for the tax manipulation purpose. However, we show that some tax manipulation still arises with the optimal tariff. The reason is that the tax manipulation by the MNE leads to more production in the domestic market which can alleviate allocative inefficiency due to monopoly power.

We next extend our analysis to an oligopolistic market structure in the home finalgood market. As the MNE has an incentive to produce more from profit-shifting motives, it may have strategic effects vis-a-vis its rival firms in the final-good market. The rival firms respond by reducing their outputs, which leads to lower profits for them in the case of strategic substitutes. This implies that tax-induced FDI by the MNE has spillover effects that reduce tax revenues from the other domestic firms as well as the MNE.

We also consider implications of the ALP when there is a single foreign supplier which has market power. If the input purchased by the downstream rivals is considered as a comparable input used by the MNE and the CUP method is applied by the regulator, the price set by the foreign supplier affects the internal price of the MNE. Thus, the imposition of the ALP in this case may have implications of strategic price setting of the single input supplier in Foreign. We show that the CUP method also has implications for the MNE's incentives to supply to its downstream rival. As is standard in the verticalintegration literature, there are trade-offs between raising rival's costs and profit losses for the upstream firm when the MNE engages in input foreclosure to the rival downstream firm. In our set-up, there is an additional channel through which foreclosure can be beneficial via transfer pricing, because the input foreclosure increases the rival firm's input acquisition costs, which the tax authorities regard as the benchmark transfer price in the CUP regime. As a result, we find that the MNE may refrain from supplying to the rival downstream firm even if it is more efficient than the foreign input supplier, providing a novel theory of market foreclosure.

Our paper is at the intersection of international trade and public economics. Horst (1971) initiated the theory of multinational firms in the presence of different tariff and tax rates across countries and explored the profit-maximizing strategy for a monopolistic firm selling to two national markets, that is, how much it should produce in each country and what the optimal transfer price for goods exported from the parent to the subsidiary would be. Horst (1971) and subsequent papers (such as Batra and Hadar, 1979; Itagaki, 1979,1981 ) show that MNE's optimum price would be either the highest or the lowest possible allowed by the limits of government rules and regulations, depending on tax and 
tariff schedules among countries. Kant (1988) shows how an interior transfer price can be derived endogenously in the presence of so-called "concealment costs."

In our model, the decision making process is centralized. ${ }^{6}$ Hirshleifer (1956) initiated another strand of literature on transfer pricing with "decentralized" decision making process inside the firm. In this framework, transfer prices are instruments used by headquarters to control separate divisions from pursuing their own interests. For instance, Hirshleifer (1956) assumes that decision-making across branches is decentralized and the transfer prices in his model are chosen to align the production decisions of the various divisions. Bond (1980) extends the analysis of optimal transfer pricing to a case where branches of a vertically integrated enterprise are located in multiple jurisdictions with different tax rates. He shows that the optimal transfer prices trade off the gains from tax avoidance against the efficiency losses associated from resource misallocation.

In the presence of oligopoly, the transfer-pricing literature with decentralized decisions further considers strategic effects of transfer pricing as an instrument of strategic delegation. For instance, Alles and Datar (1998) show how cost-based transfer prices can be manipulated to dampen competition and sustain higher market prices in a closed economy. Schjelderup and Sorgard (1997) is one of the first papers that analyze transfer pricing for decentralized MNEs with an oligopolistic market structure. However, they do not deal with the ALP.

Kato and Okoshi (2017) also adopt a decentralized decision structure and consider the optimal location of production facilities in the presence of tax differences between countries, and the effect of the ALP on the location choice. Their paper is closely related to ours in the sense that their model also consider both strategic and tax-manipulation effects of transfer pricing. However, both the set-up (including the decision making process) and focus of their paper are very different from ours. They consider a setting in which an MNE faces competition in the downstream market but the MNE is a single input supplier for both its downstream subsidiary and its rival. In their model, the imposition of the ALP is equivalent to the prohibition of price discrimination for the MNE's upstream monopoly. Moreover, we consider other upstream suppliers and analyze the outsourcing vs. FDI decision, whereas their focus is on the location choice of upstream monopoly production facility.

Whether the MNE's decision is centralized or decentralized, there are only a few

\footnotetext{
${ }^{6}$ Nielsen et al. (2008) explicitly examine conditions under which a centralized decision is preferred to a decentralized decision.
} 
studies that theoretically investigate the ALP under imperfect competition. Samuelson (1982) is the first study to point out that for an MNE subject to the ALP principle, the arm's length reference price itself can be partially determined by the firm's activities. In a similar vein, Gresik and Osmundsen (2008) consider transfer pricing in a vertically integrated industries in the absence of transactions between independent entities. More specifically, they examine the implications of the ALP as a transfer price regulation when all firms are vertically integrated and the only source of comparable data may be from transactions between affiliated firms. In our framework with imperfect competition in both upstream and downstream markets, the reference price for an MNE is determined by an outsider firm which recognizes the strategic effects of its price decision on its input demand via the transfer price of the MNE. It is shown that the outsider has an incentive to set a lower price compared to the case without linkage via the transfer price.

The rest of the paper is organized in the following way. Section 2 introduces the basic set-up of a monopoly model with transfer pricing. We first analyze the incentive to engage in FDI due to a tax differential between the source and the host countries and the optimal transfer price with the ALP. We then explore implications of such FDI for the efficiency of global sourcing and identify the wedge between the efficient outcome and the market equilibrium. We also explore implications of the ALP for social welfare and dual sourcing incentives. Section 3 considers import tariffs as countermeasures against profit-shifting. We derive the optimal tariff in the presence of transfer pricing. Section 4 extends the analysis to a duopoly setting to examine implications of strategic interactions in the finalgood market. We show that profit-shifting strategy of the MNE has further consequences for tax revenues from its rival due to strategic effects. In section 5, we analyze how the input market price can be endogenized with the imposition of the CUP method in the presence of a single foreign input supplier. In particular, we uncover an additional motive for foreclosure arising from tax concerns, therefore providing a novel theory of vertical foreclosure. Section 6 concludes the paper. 


\section{The Monopoly Model with FDI: Transfer Pricing and the ALP}

\subsection{The Basic Set-up}

There are two countries, Home and Foreign, with different corporate tax rates, $t>\widetilde{t}^{7}$ There exists a monopolistic final-good producer. The headquarters that produces the final good is immobile and tied to Home while its intermediate input is sourced from Foreign. There are two possible channels to procure the input from Foreign. The headquarters purchases the input from a foreign competitive open market at the price of $\varpi$ (in section 4 , we consider the external sourcing with market power and endogenize $\varpi$ ). Alternatively, the headquarters establishes its own input-production plant in Foreign through FDI. We assume that one unit of the input is converted to one unit of the final good without incurring any additional costs and that the input production is subject to constant returns to scale. We also assume away the costs associated with FDI. ${ }^{8}$ The subsidiary's unit cost of the input production (i.e., marginal production cost) is given by $c$. The final good is consumed only in Home.

The MNE can choose an internal transfer price, $\gamma$, when its foreign subsidiary supplies its input to the headquarters. Without any tax rate differential between the two countries, the MNE's optimal internal transaction price for the input is simply its MC, $c$, in order to eliminate any double marginalization problem. However, with different tax rates between Home and Foreign, the MNE can choose $\gamma$ as a mechanism to shift profits to minimize its tax burden. Figure 1 describes the basic set-up.

\subsection{The Benchmark Case: No Regulation (NR)}

As a benchmark case, we first consider the choice of internal price by the MNE when there is no regulation and the MNE can set any internal price. In this case, the MNE sets its internal price, $\gamma$, and output, $q$, to maximize the following global profits after tax:

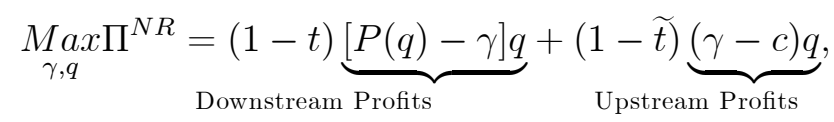

\footnotetext{
${ }^{7}$ Foreign parameters and variables are denoted by "tilde".

${ }^{8}$ If there exists a fixed cost to set up the subsidiary, FDI becomes less likely. However, the essence of our results would not change.
} 


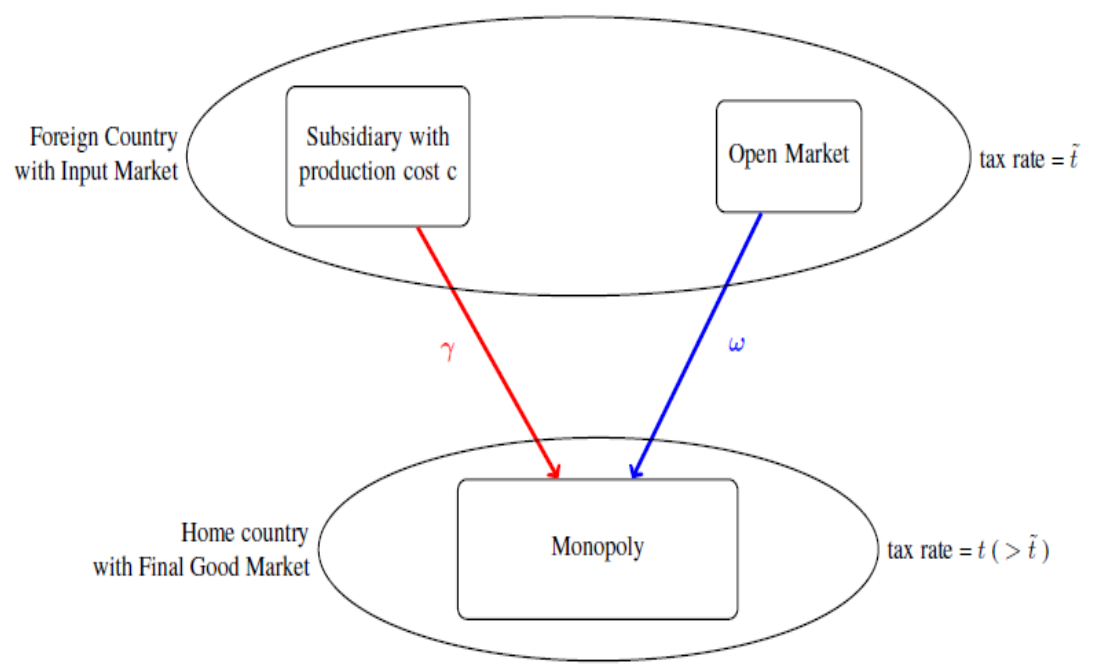

Figure 1: Monopolistic MNE with Transfer Price

where $P(q)$ is the downward sloping inverse demand function the monopolist faces. We should mention that the decision making is assumed to be centralized. That is, with the MNE's objective function above, the headquarters producing the final good makes an output decision that would maximize the overall firm profit, not just the profit of the downstream division.

Note that the objective function of the monopolist can be rewritten as

$$
\Pi^{N R}=(1-t)\left[P(q)-\xi^{N R}\right] q
$$

where

$$
\xi^{N R} \equiv \frac{(1-\widetilde{t}) c-(t-\widetilde{t}) \gamma}{1-t}
$$

That is, the MNE facing different tax rates across countries behaves as if its marginal production cost were $\xi^{N R}$, which can be considered as the MNE's "perceived marginal cost (PMC)" of production adjusted for transfer price induced by the differential tax rates across countries. Since the MNE's profit decreases as $\xi^{N R}$ increases, the monopolist's optimal choice of $\gamma$ is equivalent to the choice of $\gamma$ that minimizes $\xi^{N R}$, regardless of its output level. Note that $\xi^{N R}$ is decreasing in its internal transfer price, $\gamma$, because it can be used as a vehicle to shift profit from the high-tax country (Home) to the low-tax country (Foreign).

As pointed out by Horst (1971), it immediately follows that the optimal choice is to 
set $\gamma$ as high as possible with the constraint that the downstream profit is non-negative. This implies that all profits from a high-tax country will be shifted towards to a lowtax country in the absence of any regulation. This simple model illustrates the need for regulations to counter such MNE's profit-shifting motives to reduce the tax burden.

\subsection{The Arm's Length Principle (ALP)}

In reality, there are regulations that would prevent the choice from being a corner solution and limit the MNE's profit-shifting motives. The most-widely adopted and agreed-upon standard practice is the "Arm's Length Principle (ALP)", which requires intrafirm transfer prices to mimic the market price that would be obtained in comparable uncontrolled transactions at arm's length, as discussed in the Introduction. Even though this principle is conceptually sound and straightforward, its implementation as a regulatory policy may be difficult and subject to different interpretations. For instance, in the context of monopoly, such a "comparability analysis" is unlikely to be feasible, simply because there is no comparable transactions as it is the only firm that produces the final good; no other firms acquire similar inputs. Even if similar inputs are transacted in the market by other firms for different purposes, the monopolist may argue that the available inputs are not suitable to meet its specifications and that is a reason why they are engaged in its own production in the first place. In other words, what constitutes a similar input may not be clear-cut and subject to disputes unless comparable inputs are identical.

In our analysis, we consider two alternative scenarios in which the ALP is implemented.

1. CUP Method with Comparable Input Available in the Market: We assume that if a comparable input is available in the market, the firm is required to use the comparable market price as the internal transfer price.

2. Cost-Plus Method without Comparable Input Available in the Market: If a comparable input is not transacted in the market, then the CUP method cannot be applied and the lack of comparable inputs transacted by uncontrolled parties necessitates the use of other methods to regulate transfer pricing. In such a case, we assume that the regulator uses the $\mathrm{CP}$ method which mandates that the transfer price should reflect the production cost of the input internally transacted. However, the true production cost is typically non-observable to tax authorities and hard to ascertain. As a result, it can be manipulated at certain costs. 
Our analysis proceeds in the following working assumptions. In the monopoly case, we consider the "cost plus" scenario as the main focus, which we believe is more realistic because the monopolistic downstream firm is the only firm that demands such an input. ${ }^{9}$ In sections 3 and 4 where we analyze the duopoly case, we deal with both cases.

\subsection{The "Cost Plus" Method and Concealment Costs}

We analyze the choice of internal transfer price when the CP method is adopted as an application of the ALP for the monopoly case. As shown in the previous subsection, without any external or regulatory restriction on the transfer price, all profits would be shifted towards to a low-tax country with FDI being used as a vehicle. However, this type of behavior can be a violation of tax laws. We thus explore implications of institutional constraints on the internal transfer price.

To this end, we assume that a deviation of MNE's internal price from its true MC entails costs of $\Psi(\gamma-c, q)$. This could be interpreted as concealment costs or could reflect expected punishment for the deviation as in Allingham and Sandmo (1972) and Kant (1988). For analytical tractability, we assume the concealment costs are separable in the deviation of the internal price from its true MC and the amount of inputs transferred, that is, $\Psi(\gamma-c, q)=\phi(\gamma-c) q$ with $\phi^{\prime}>0, \phi^{\prime \prime}>0$, and $\phi^{\prime}(0)=0$, as in Egger and Seidel (2013). This specification states that concealment costs increase with a deviation of the transfer price from its true MC and the amount of inputs transferred. In addition, concealment costs are convex in the degree of deviations with the usual Inada condition. The convexity assumption is standard in the literature on transfer pricing and tax evasion. It may reflect additional costs to justify or conceal the difference between the reported and the true marginal production cost of the input (Haufler and Schjelderup, 2000). The dependence of concealment costs on the amount of inputs transferred can reflect an increased probability of detection with a larger scale of operation and transfer. In particular, the linearity assumption can be justified if we interpret concealment costs as an expected penalty that is linear in the amount of transactions. Moreover, the assumption of linear concealment costs in the MNE's output allows a very clean characterization concerning the MNE's optimal transfer price and its sourcing decision. ${ }^{10}$ As in Gresik and Odmundsen (2008), we assume that only the high-tax country (Home) has incentives

\footnotetext{
${ }^{9}$ The CUP case for the monopolist can also be analyzed in a straightforward manner.

${ }^{10}$ In subsection 2.6, we consider a more general form of concealment costs: $\Psi(\gamma-c, q)=\phi(\gamma-c) \mu(q)$. When $\mu$ is convex in $q$, dual sourcing may be optimal and section 2.6 explores implications of the ALP in such a case.
} 
to audit for evidence of profit shifting; auditing is self-defeating for the low-tax country (Foreign) because it only reduces tax revenues for Foreign.

\subsubsection{The Optimal Transfer Price with Concealment Costs}

More specifically, with concealment costs linear in the output, the MNE's post-tax profit function is given by ${ }^{11}$

$$
\begin{aligned}
& \Pi=(1-t) \underbrace{[P(q)-\gamma] q}_{\text {Downstream Profits }}+(1-\widetilde{t}) \underbrace{(\gamma-c) q}_{\text {Upstream Profits }}-\underbrace{\phi(\gamma-c) q}_{\text {Concealment Costs }} \\
& =(1-t)[P(q)-\xi] q,
\end{aligned}
$$

where

$$
\begin{aligned}
\xi & \equiv \gamma-\frac{(1-\widetilde{t})(\gamma-c)}{1-t}+\frac{\phi(\gamma-c)}{1-t}=\frac{(1-\widetilde{t}) c-(t-\widetilde{t}) \gamma+\phi(\gamma-c)}{1-t} \\
& =\xi^{N R}+\frac{\phi(\gamma-c)}{1-t} .
\end{aligned}
$$

Thus, the optimal choice of the transfer price $\gamma^{*}$ is equivalent to minimize the MNE's PMC, $\xi$, which is adjusted for transfer price induced by differential tax rates and concealment costs, and implicitly defined by

$$
t-\tilde{t}=\phi^{\prime}(\gamma-c)
$$

Thus, the optimal $\gamma^{*}$ can be derived as

$$
\gamma^{*}=c+\phi^{\prime-1}(t-\widetilde{t})>c .
$$

For instance, if we specify the $\phi$ function as follows: $\phi(\gamma-c)=\frac{k}{2}(\gamma-c)^{2}$, where a higher $k$ means better institutional monitoring and makes it more costly for the MNEs to engage in profit shifting, then we have $\gamma^{*}=c+\frac{t-\widetilde{t}}{k}{ }^{12}$ The optimal choice of the transfer

\footnotetext{
${ }^{11}$ In the expression for the MNE's total post-tax profit, we interpret concealment costs as an expected penalty for profit shifting, which creates a new liability (Gresik and Osmundsen, 2008). With this interpretation of concealment costs, they are not part of the taxable profits. However, this is not a crucial assumption and our qualitative results are robust to including them in the taxable profits at either Home or Foreign, depending on where concealment costs are incurred.

${ }^{12}$ We implicitly assume that concealment costs (i.e., $k$ ) are sufficiently high under regulation to warrant an interior solution, that is, all downstream profits are not shifted to the host country with a lower tax
} 
price is consistent with empirical findings. Clausing (2003), for example, shows that the US intrafirm import price becomes higher as the tax rate of the exporting country becomes lower. Note that the different prediction is obtained without concealment costs.

\subsubsection{FDI vs. Outsourcing}

Let $\xi^{*}$ be the minimized PMC with the choice of optimal transfer price $\gamma^{*}$. Then, the MNE's profit from FDI can be written as

$$
\Pi^{F D I}=(1-t)\left[P(q)-\xi^{*}\right] q
$$

whereas the monopolist's profit from outsourcing can be written as

$$
\Pi^{O S}=(1-t)[P(q)-\varpi] q .
$$

Thus, the monopolist's sourcing decision boils down to a simple comparison between $\xi^{*}$ and $\varpi$. FDI takes place if and only if $\xi^{*}<\varpi$.

We first show the following proposition, which implies that the MNE's after-tax global profit is greater due to tax manipulation compared to the case where the firm transfers its input at its MC, $c$.

Proposition 1. $\xi^{*}<c$.

Proof. Note that $\xi^{*}$ can be written as

$$
\xi^{*}=c-\lambda,
$$

where $\lambda \equiv \frac{(t-\widetilde{t})\left(\gamma^{*}-c\right)-\phi\left(\gamma^{*}-c\right)}{1-t}$. Using the FOC that defines $\gamma^{*}$, we find that the numerator of $\lambda$ is positive because

$$
(t-\widetilde{t})\left(\gamma^{*}-c\right)-\phi\left(\gamma^{*}-c\right)=\left(\gamma^{*}-c\right)[\underbrace{\phi^{\prime}\left(\gamma^{*}-c\right)-\frac{\phi\left(\gamma^{*}-c\right)}{\left(\gamma^{*}-c\right)}}_{>0 \text { by the convexity of } \phi}]>0 .
$$

Therefore, $\xi^{*}<c$.

rate. 
The MNE's profit is as if its cost were the PMC of $\xi^{*}$ which is lower than its true MC of $c$. As a result, the following corollary is immediate.

Corollary 1. Consumer surplus increases with profit shifting via transfer pricing.

As the MNE uses transfer pricing to shift profits from the high-tax country to the lowtax country, it produces more with a lower PMC than its true MC. As a result, consumer surplus increases.

In addition, Proposition 1 implies that the MNE's sourcing decision could be inefficient from the viewpoint of the global production efficiency (see Figure 2). The global efficiency requires that FDI takes place if and only if $c<\varpi$. However, the profit-shifting motives due to tax differences across countries create a wedge of $\lambda(>0)$, which distorts the MNE's sourcing decision. We can also easily show that the wedge is increasing in the tax-rate differential across countries because of the following comparative statics results.

Lemma 1. $\frac{d \xi^{*}}{d t}<0$ and $\frac{d \xi^{*}}{d \widetilde{t}}>0$.

Proof. By the envelope theorem, we have

$$
\frac{d \xi^{*}}{d t}=\frac{\partial \xi^{*}}{\partial t}=-\frac{(1-\widetilde{t})\left(\gamma^{*}-c\right)-\phi(\gamma-c)}{(1-t)^{2}}
$$

which is negative because $(1-\widetilde{t})\left(\gamma^{*}-c\right)-\phi(\gamma-c)>(t-\widetilde{t})\left(\gamma^{*}-c\right)-\phi\left(\gamma^{*}-c\right)>0$ as shown in the proof of Proposition 1. Similarly, we obtain

$$
\frac{d \xi^{*}}{d \widetilde{t}}=\frac{\partial \xi^{*}}{\partial \widetilde{t}}=\frac{\gamma^{*}-c}{1-t}>0
$$

Thus, with respect to inefficiency of internal sourcing, we obtain the following proposition.

Proposition 2. With $t>\widetilde{t}, F D I$ is undertaken in equilibrium if and only if $\xi^{*}<\varpi$. Thus, if $c \in(\varpi, \varpi+\lambda)$ (where $\left.\lambda \equiv \frac{(t-\widetilde{t})\left(\gamma^{*}-c\right)-\phi\left(\gamma^{*}-c\right)}{1-t}>0\right)$, inefficient FDI arises. The wedge $\lambda$ increases in the tax differential between Home and Foreign (i.e., $t-\widetilde{t})$. 


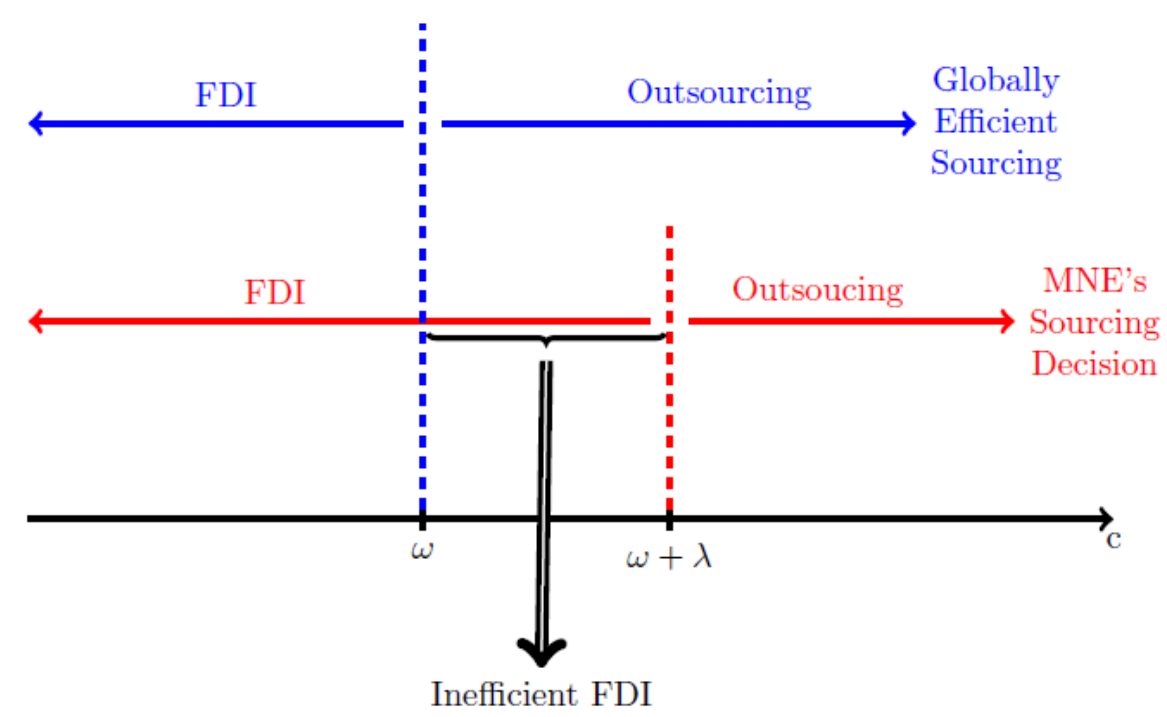

Figure 2: Globally Efficient Sourcing vs. MNE's Sourcing Decision

\subsubsection{A Parametric Example}

We now specify the $\phi$ function as follows: $\phi(\gamma-c) \equiv \frac{k}{2}(\gamma-c)^{2}$. Then we have

$$
\gamma^{*}=c+\frac{t-\tilde{t}}{k}
$$

By plugging this back into $\xi$, we can easily verify

$$
\xi^{*}=c-\frac{(t-\widetilde{t})^{2}}{2 k(1-t)}
$$

This implies that FDI is undertaken if and only if

$$
c<\varpi+\frac{(t-\widetilde{t})^{2}}{2 k(1-t)}
$$

That is, unless the MNE's internal production cost does not exceed the open market price by $\frac{(t-\widetilde{t})^{2}}{2 k(1-t)}$, FDI takes place. In particular, with $c \in\left(\varpi, \varpi+\frac{(t-\widetilde{t})^{2}}{2 k(1-t)}\right)$, FDI is inefficient, but is still optimal from the perspective of the MNE because of tax manipulation via transfer pricing. 


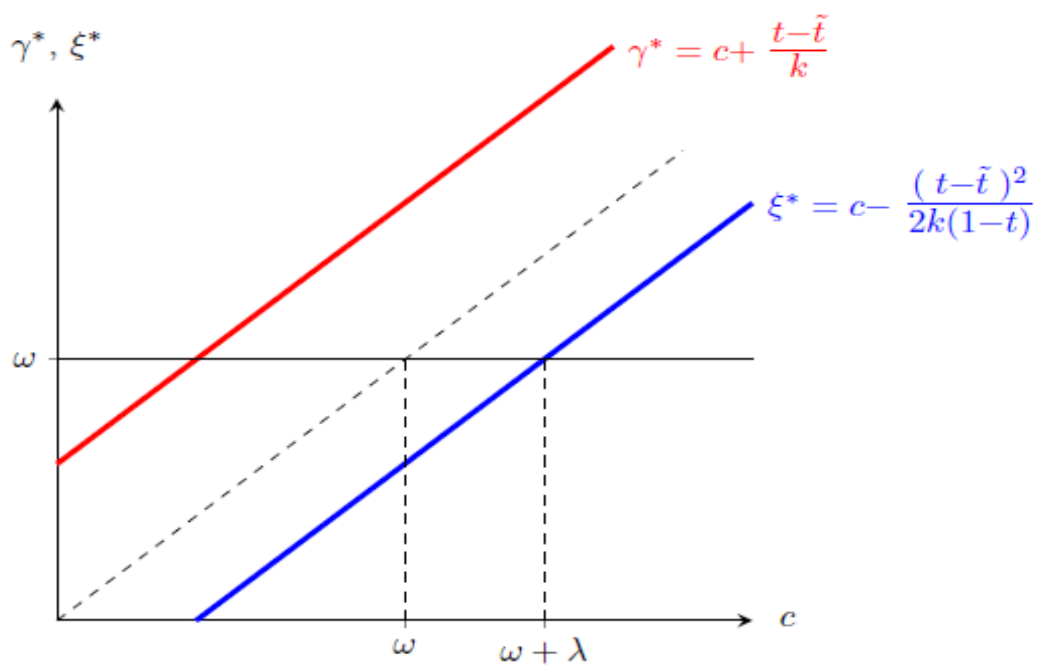

Figure 3: Optimal Transfer Price and "Perceived" MC

\subsection{Impact of the ALP on Social Welfare}

The home government can limit the MNE's tax manipulation through the ALP, which would increase tax revenue for Home. However, it would reduce consumer surplus because the MNE contracts its output, as well as it would reduce the MNE's profits. In this subsection, we evaluate social welfare with and without the ALP to assess the welfare impact of the ALP. More specifically, we show that social welfare in Home may decrease as a result of the ALP regulation. To demonstrate this, we assume that the concealment costs are the real resource costs devoted to the concealment activities. ${ }^{13}$ For illustration with closed-form solutions, we further assume linear demand and quadratic concealment costs: $P(q)=1-q$ and $\phi(\gamma-c)=\frac{k}{2}(\gamma-c)^{2}$.

Let us begin with the derivation of social welfare under no regulation. As we have shown, in the absence of regulation the MNE has incentive to raise the transfer price $\gamma$ up to the level that completely eliminates the profits of the downstream division. That is, the MNE will choose $\gamma$ such that the profit-maximizing quantity induces the price to be equal to the transfer price $\gamma$. Viewing $\xi^{N R}$ in (1) as a function of $\gamma$ and $q(\xi)=(1-\xi) / 2$ as the optimal quantity the MNE chooses when faced with the PMC of $\xi$, we can express the condition that determines the optimal transfer price as $P\left(q\left(\xi^{N R}(\gamma)\right)\right)=\gamma$. This gives

\footnotetext{
${ }^{13}$ We can make the same qualitative welfare comparison when the concealment costs are interpreted as the expected penalty that the MNE has to pay to the home government and hence considered as a transfer in social welfare calculations. For details, see the Appendix.
} 
us the optimal transfer price, $\gamma_{0}^{*}$, as

$$
\gamma_{0}^{*}=\frac{1-t+(1-\tilde{t}) c}{2-t-\tilde{t}}
$$

We substitute this back into (1) to obtain

$$
\xi^{N R}\left(\gamma_{0}^{*}\right)=\frac{2 c(1-\tilde{t})-t+\tilde{t}}{2-t-\tilde{t}}, q\left(\xi^{N R}\left(\gamma_{0}^{*}\right)\right)=\frac{(1-c)(1-\tilde{t})}{2-t-\tilde{t}}
$$

Social welfare is defined to be the sum of consumer surplus, $C S$, producer surplus, $P S$, and tax revenue, $T R$. In the absence of regulation, we have

$$
\begin{aligned}
C S_{0} & =\int_{0}^{q\left(\xi^{N R}\left(\gamma_{0}^{*}\right)\right)} P(q) d q-P\left(q\left(\xi^{N R}\left(\gamma_{0}^{*}\right)\right)\right) q\left(\xi^{N R}\left(\gamma_{0}^{*}\right)\right) \\
P S_{0} & =\Pi^{N R}=(1-t)\left[P\left(q\left(\xi^{N R}\left(\gamma_{0}^{*}\right)\right)\right)-\xi^{N R}\left(\gamma_{0}^{*}\right)\right] q\left(\xi^{N R}\left(\gamma_{0}^{*}\right)\right), \\
T R_{0} & =t\left[P\left(q\left(\xi^{N R}\left(\gamma_{0}^{*}\right)\right)\right)-\gamma_{0}^{*}\right] q\left(\xi^{N R}\left(\gamma_{0}^{*}\right)\right)(=0),
\end{aligned}
$$

respectively. Consequently, we obtain social welfare under no regulation as

$$
W_{0}=\int_{0}^{q\left(\xi^{N R}\left(\gamma_{0}^{*}\right)\right)} P(q) d q-\xi^{N R S P}\left(\gamma_{0}^{*}\right) q\left(\xi^{N R}\left(\gamma_{0}^{*}\right)\right)
$$

where

$$
\xi^{N R S P}\left(\gamma_{0}^{*}\right) \equiv(1-t) \xi^{N R}\left(\gamma_{0}^{*}\right)+t \gamma_{0}^{*}=c+\tilde{t}\left(\gamma_{0}^{*}-c\right)=c+\frac{\tilde{t}(1-t)(1-c)}{2-t-\tilde{t}}
$$

representing the MC of FDI production from the perspective of the social planner of Home under no regulation (NR). It consists of the physical production cost of $c$ and tax transfer to the host country (i.e., Foreign). Note that the MNE's production level is determined not by the social planner's $\xi^{N R S P}\left(\gamma_{0}^{*}\right)$ but by its perceived $\mathrm{MC}$ of $\xi^{N R}\left(\gamma_{0}^{*}\right)$.

Next, we derive social welfare under the ALP. As we have shown earlier, the MNE chooses $\gamma$ so as to minimize $\xi=[(1-\tilde{t}) c-(t-\tilde{t}) \gamma+\phi(\gamma-c)] /(1-t)$. The optimal $\gamma$ is given by

$$
\gamma^{*}=c+\frac{t-\tilde{t}}{k}
$$


and hence we have

$$
\xi\left(\gamma^{*}\right)=c-\frac{(t-\tilde{t})^{2}}{2 k(1-t)}, q\left(\xi\left(\gamma^{*}\right)\right)=\frac{1}{2}(1-c)+\frac{(t-\tilde{t})^{2}}{4 k(1-t)} .
$$

To ensure that the above expressions are valid (i.e., the downstream profit is non-negative), we impose the following condition: $P\left(q\left(\xi\left(\gamma^{*}\right)\right)\right) \geq \gamma^{*}+\phi\left(\gamma^{*}-c\right)$, which is equivalent to

$$
k \geq \frac{(t-\tilde{t})[t-\tilde{t}+2(1-t)(2+t-\tilde{t})]}{2(1-t)(1-c)} \equiv \underline{k} .
$$

With the maintained assumption of $k \geq \underline{k}$, the expressions for $C S, P S$, and $T R$ are the same as in the case of no regulation, except that $\xi^{N R}\left(\gamma_{0}^{*}\right)$ is replaced by $\xi\left(\gamma^{*}\right)$. Consequently, we obtain social welfare in this case as

$$
W=\int_{0}^{q\left(\xi\left(\gamma^{*}\right)\right)} P(q) d q-\xi^{S P}\left(\gamma^{*}\right) q\left(\xi\left(\gamma^{*}\right)\right)
$$

where

$$
\xi^{S P}\left(\gamma^{*}\right) \equiv(1-t) \xi\left(\gamma^{*}\right)+t \gamma^{*}=c+\frac{(t-\tilde{t})(t+\tilde{t})}{2 k}
$$

representing the MC of FDI production from the perspective of the social planner of Home under the ALP, which includes concealment costs.

To see the welfare impact of the ALP, we first notice that in the presence of concealment cost, the MNE under the ALP does not raise $\gamma$ as much as it does under no regulation. As a consequence, $\xi^{N R}\left(\gamma_{0}^{*}\right)<\xi\left(\gamma^{*}\right)$, and hence $q\left(\xi^{N R}\left(\gamma_{0}^{*}\right)\right)>q\left(\xi\left(\gamma^{*}\right)\right)$. That is, the ALP induces the MNE to produce less, meaning smaller $C S$.

As Figure 4 shows, therefore, the ALP unambiguously reduces social welfare if $\xi^{N R S P}\left(\gamma_{0}^{*}\right)<$ $\xi^{S P}\left(\gamma^{*}\right)$. It is readily shown that this condition is equivalent to

$$
k<\frac{(t+\tilde{t})(t-\tilde{t})(2-t-\tilde{t})}{2 \tilde{t}(1-t)(1-c)} \equiv \hat{k}^{S P} .
$$

We can readily show that $\hat{k}^{S P}>\underline{k}$. Thus, we find that there is a region for $k$, i.e., $\left(\underline{k}, \hat{k}^{S P}\right]$, such that the ALP unambiguously reduces social welfare. The reason why the ALP reduces social welfare when $k$ is small is that the MNE would raise $\gamma$ so much that the resulting large concealment cost significantly reduces social welfare.

This result suggests that the desirability of the ALP in terms of social welfare crucially 


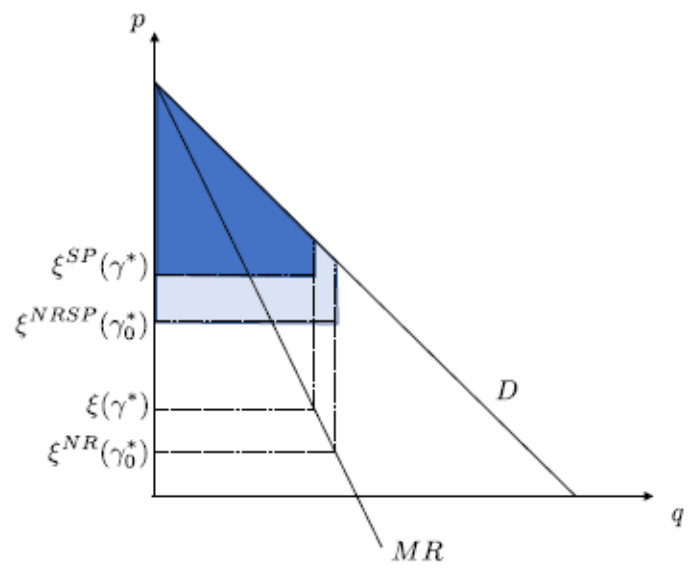

Figure 4: Impact of the ALP on Social Welfare

depends on the quality of institutional monitoring (represented by parameter $k$ ). Better institutional monitoring and the ALP regulation are complementary. Imposing the ALP without quality monitoring in place can be counterproductive. Indeed, we calculate both $W_{0}$ and $W$ in the case where $c=0.3$ and $k=3$, and show that $W_{0}>W$ holds if $t$ is large or $\tilde{t}$ is small, as Figure 5 illustrates.

Although the ALP discourages MNE's profit shifting, it would induce the MNE to produce less and hence could lead to the deterioration of social welfare. This basic message regarding the welfare impact of the ALP will also be valid in a duopoly case that we examine in section 4.

\subsection{Non-Linear Concealment Costs and Dual Sourcing}

With the concealment costs linear in the amount internally transferred, $q$ (with an inflated price, $\gamma$ ), the MNE will procure its input only from a single source (i.e., either all from the internal source or all from the open market). However, if the concealment costs are convex in $q$, the MNE may source its inputs from both the internal and external sources. To see this, let us assume that $\Psi(\gamma-c, q)=\phi(\gamma-c) \mu(q)$ with $\mu^{\prime}$ and $\mu^{\prime \prime}>0$. Then we have

$$
\begin{aligned}
\Pi & =(1-t)[P(q)-\gamma] q+(1-\widetilde{t})(\gamma-c) q-\phi(\gamma-c) \mu(q) \\
& =(1-t)\left(\left[P(q)-\frac{(1-\widetilde{t}) c-(t-\widetilde{t}) \gamma}{1-t}\right] q-\frac{\phi(\gamma-c)}{1-t} \mu(q)\right)
\end{aligned}
$$




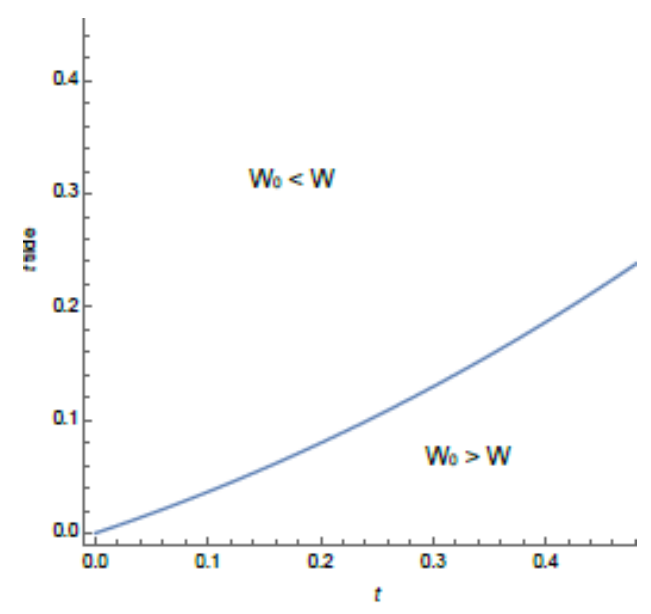

Figure 5: Welfare Impact of the ALP

Thus, given $\gamma$, the PMC from internal sourcing via FDI, $\xi$, is not constant and can be expressed as

$$
\xi(q ; \gamma)=\frac{[(1-\widetilde{t}) c-(t-\widetilde{t}) \gamma]+\phi(\gamma-c) \mu^{\prime}(q)}{1-t} .
$$

This also implies that depending on the production quantity, the optimal transfer price changes. For a given quantity, $q$, the transfer price that minimizes the total production cost $[(1-\widetilde{t}) c-(t-\widetilde{t}) \gamma] q+\phi(\gamma-c) \mu(q)$ is given by the following FOC:

$$
(t-\widetilde{t}) q=\phi^{\prime}(\gamma-c) \mu(q) .
$$

Totally differentiating (2), we can easily verify that the optimal internal price $\gamma^{*}(q)$ is decreasing in $q$ :

$$
\frac{d \gamma}{d q}=\frac{\left[(t-\widetilde{t})-\phi^{\prime}(\gamma-c) \mu^{\prime}(q)\right]}{\phi^{\prime \prime}(\gamma-c) \mu(q)}<0
$$

because $\phi^{\prime}(\gamma-c) \mu^{\prime}(q)>\phi^{\prime}(\gamma-c) \frac{\mu(q)}{q}=(t-\widetilde{t})$ holds from the convexity of $\phi$ and (2).

Let $q_{I}$ and $q_{O}$ denote the amount of inputs from the internal source (i.e., FDI) and the outside source (i.e., the open market), respectively. Then, the optimal sourcing decision can be derived from the following optimization problem:

$$
\underset{q_{I}, q_{O}, \gamma}{\operatorname{Min}} \frac{[(1-\widetilde{t}) c-(t-\widetilde{t}) \gamma] q_{I}+\phi(\gamma-c) \mu\left(q_{I}\right)}{1-t}+\varpi q_{O}
$$


subject to

$$
q_{I}+q_{O}=q \text { and } q_{I}, q_{O} \geq 0 .
$$

The Lagrangian for this problem can be written as

$$
£=\frac{[(1-\widetilde{t}) c-(t-\widetilde{t}) \gamma] q_{I}+\phi(\gamma-c) \mu\left(q_{I}\right)}{1-t}+\varpi q_{O}+\eta\left[q-\left(q_{I}+q_{O}\right)\right],
$$

where $\eta$ is the Lagrangian multiplier associated with the constraint $q_{I}+q_{O}=q$.

The FOCs can be written as

$$
\begin{aligned}
\frac{\partial £}{\partial q_{I}} & =\xi\left(q_{I} ; \gamma\right)-\eta \geq 0, \frac{\partial £}{\partial q_{I}} q_{I}=0, \\
\frac{\partial £}{\partial q_{O}} & =\varpi-\eta \geq 0, \frac{\partial £}{\partial q_{O}} q_{O}=0, \\
\frac{\partial £}{\partial \gamma} & =\frac{-(t-\widetilde{t}) q+\phi^{\prime}(\gamma-c) \mu(q)}{1-t}=0 .
\end{aligned}
$$

Let $\widehat{q}$ be the unique output level such that

$$
(t-\widetilde{t}) q=\phi^{\prime}(\gamma-c) \mu(q), \xi(q ; \gamma) \equiv \frac{[(1-\widetilde{t}) c-(t-\widetilde{t}) \gamma]+\phi(\gamma-c) \mu^{\prime}(q)}{1-t}=\varpi .
$$

Then, the internal production is optimal up to $\widehat{q}$ and, beyond $\widehat{q}$, outsourcing is optimal. Therefore, the following two types of sourcing behavior are possible: (i) the dual sourcing with $q_{I}>0, q_{O}>0$ and (ii) the internal sourcing with $q_{O}=0$. With the dual sourcing, we have $\xi\left(q_{I} ; \gamma\right)=\varpi$. This would be the case when $q>\widehat{q}$. Then, the amount of internal sourcing is given by $q_{I}=\widehat{q}$, and the rest is outsourced, i.e., $q_{O}=(q-\widehat{q})$. On the other hand, with the internal sourcing, we have $\xi\left(q_{I} ; \gamma\right)=\eta<\varpi$. This would be the case when $q<\widehat{q}$.

Which sourcing will be adopted depends on the size of the market. Let $M R(q)$ be the marginal revenue curve corresponding to the inverse market demand $P(q)$. Then, if $M R(\widehat{q})>\varpi$, the dual sourcing arises. If not, then the internal sourcing alone arises. In the latter case, the MNE solves

$$
\underset{q_{I}, \gamma}{\operatorname{Min}} \frac{[(1-\widetilde{t}) c-(t-\widetilde{t}) \gamma] q_{I}+\phi(\gamma-c) \mu\left(q_{I}\right)}{1-t},
$$


which defines $\gamma(q)$. Thus, the cost function up to $\widehat{q}$ is given by

$$
\begin{aligned}
C(q) & =\frac{[(1-\widetilde{t}) c-(t-\widetilde{t}) \gamma(q)] q+\phi(\gamma(q)-c) \mu(q)}{1-t} \\
C^{\prime}(q) & =\frac{\partial C}{\partial q}+\frac{\partial C}{\partial \gamma} \frac{\partial \gamma}{\partial q}=\frac{[(1-\widetilde{t}) c-(t-\widetilde{t}) \gamma(q)]+\phi(\gamma(q)-c) \mu^{\prime}(q)}{1-t}=\xi(q ; \gamma)<\varpi
\end{aligned}
$$

which is described by $\xi$ curve in Figure 6 .

As Figure 6 illustrates, with convex concealment costs, there will be internal sourcing alone if the market demand is small, but dual sourcing if the market size is large. Note that in our model, we abstract away from fixed costs of setting up a foreign subsidiary. If there are any fixed costs associated with FDI, then our model would predict that for a very small market size, the sourcing will be done by outsourcing alone, but once the market size grows enough to cover the fixed costs, the monopolist will switch to internal sourcing. If the market size becomes sufficiently large, it will engage in the dual sourcing. That is, the use of outsourcing is not monotonic with the market size if there exist the fixed costs of FDI.

To illustrate this, let us work with a parametric example of $\Psi(\gamma-c, q)=k \phi(\gamma-c) \mu(q)$, where $\phi(\gamma-c)=(\gamma-c)^{\alpha}$ with $\alpha>1$, and $\mu(q)=q^{\beta}$, that is, $\Psi(\gamma-c, q)=k(\gamma-c)^{\alpha} q^{\beta}$. Thus, $\phi^{\prime}(\gamma-c)=\alpha k(\gamma-c)^{\alpha-1}$. As a result, the optimal $\gamma$ and $q$ satisfy

$$
(t-\widetilde{t}) q=k \alpha(\gamma-c)^{\alpha-1} q^{\beta},[(1-\widetilde{t}) c-(t-\widetilde{t}) \gamma]+k \beta(\gamma-c)^{\alpha} q^{\beta-1}=(1-t) \varpi
$$

From the first equation, we have $\gamma(q)=c+\left(\frac{t-\widetilde{t}}{k \alpha}\right)^{\frac{1}{\alpha-1}} q^{-\frac{\beta-1}{\alpha-1}}$. By substituting this for $\gamma$ in the second equation, we have

$$
(1-t) c-(t-\widetilde{t})\left(\frac{t-\widetilde{t}}{k \alpha}\right)^{\frac{1}{\alpha-1}} q^{-\frac{\beta-1}{\alpha-1}}+k \beta\left[\left(\frac{t-\widetilde{t}}{k \alpha}\right)^{\frac{1}{\alpha-1}} q^{-\frac{\beta-1}{\alpha-1}}\right]^{\alpha} q^{\beta-1}=(1-t) \varpi
$$

Thus, we obtain

$$
(1-t)(c-\varpi)=\Omega q^{-\frac{\beta-1}{\alpha-1}}
$$




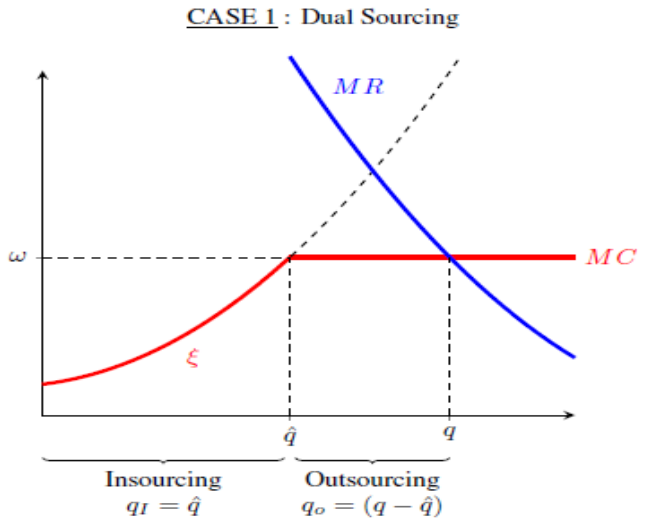

CASE 2: Insourcing Only

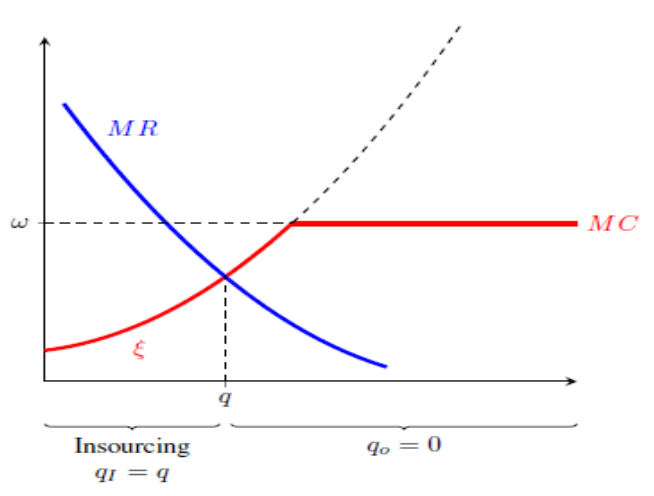

Figure 6: Internal vs. Dual Sourcing 
$q^{*}$ is given by

$$
q^{\frac{\beta-1}{\alpha-1}}=\frac{\Omega}{(1-t)(c-\varpi)},
$$

where $\Omega \equiv\left(\frac{\alpha-\beta}{\alpha}\right)(\alpha k)^{-\frac{1}{\alpha-1}}(t-\widetilde{t})^{\frac{\alpha}{\alpha-1}}$. Thus, we have

$$
\widehat{q}=\left[\frac{\Omega}{(1-t)(c-\varpi)}\right]^{\frac{\alpha-1}{\beta-1}}=\left[\frac{\alpha-\beta}{\alpha(1-t)(c-\varpi)}\right]^{\frac{\alpha-1}{\beta-1}}(\alpha k)^{-\frac{1}{\beta-1}}(t-\widetilde{t})^{\frac{\alpha}{\beta-1}} .
$$

To illustrate the idea, let us assume that $P(q)=\theta-q$, where $\theta$ represents the market size. Then, $M R=\theta-2 q$ and the $M R$ curve intersects with $\omega$ (the outsourcing $M C$ ) at $q=\frac{\theta-\omega}{2}$. Thus, dual sourcing takes place if and only if $\frac{\theta-\omega}{2}>\widehat{q}$, i.e.,

$$
\theta>2 \widehat{q}+\varpi=2\left[\frac{\alpha-\beta}{\alpha(1-t)(c-\varpi)}\right]^{\frac{\alpha-1}{\beta-1}}(\alpha k)^{-\frac{1}{\beta-1}}(t-\widetilde{t})^{\frac{\alpha}{\beta-1}}+\varpi .
$$

\subsection{Dual Sourcing and Invocation of the CUP Method}

In the previous section, we analyzed the MNE's sourcing behavior in the presence of concealment costs. The basic premise of the analysis was that for the monopoly case we have considered the applicability of the CUP method is limited if there is only one firm that produces a certain good and there are no similar transactions that can be observed and used as a benchmark. This is especially so when all input acquisitions are done internally from its foreign subsidiary. Even if an alternative input is available at the price of $\varpi$, the MNE may argue that the input available in the open market is not suitable for specific purposes of the MNE and the unavailability of suitable input is the reason for FDI aiming at internal sourcing. This allowed the MNE to use an internal transfer price that is different from $\varpi$.

However, such an argument loses the convincing appeal once the MNE engages in dual sourcing and acquires some of their input requirements through outsourcing, because it is an implicit admission that the open market input is also suitable for its final product. This implies that dual sourcing may entail a risk that it may induce the government to adopt the CUP method instead of the CP method.

In such a scenario, the MNE may respond by engaging in only internal sourcing to avoid the CUP method. Alternatively, it may choose dual sourcing even if the CUP method will be imposed and the internal price is restricted to set at $\varpi$. However, the next proposition shows that if dual sourcing invokes the use of the CUP method as an 
application of the ALP, the MNE never engages in dual sourcing when $c>\varpi$.

Proposition 3. If dual sourcing triggers the CUP method instead of the CP method, the MNE never engages in dual sourcing when $c>\varpi$.

Proof. Suppose that the MNE engages in dual sourcing when $c>\varpi$, with $q_{I}>0$ and $q_{O}>0$, where $q=q_{I}+q_{O}$. Then, its internal price should be $\gamma=\varpi$. Thus, the profit with dual sourcing that triggers the CUP method is given by

$$
\begin{aligned}
\Pi^{D} & =(1-t)\left[P\left(q_{I}+q_{O}\right)-\varpi\right]\left(q_{I}+q_{O}\right)+(1-\widetilde{t})(\varpi-c) q_{I} \\
& =(1-t)[P(q)-\varpi] q+(1-\widetilde{t})(\varpi-c) q_{I} .
\end{aligned}
$$

Alternatively, if the firm procures its input only from the outside source at the price of $\varpi$, its profits is

$$
\begin{aligned}
\Pi^{O S} & =(1-t)[P(q)-\varpi] q \\
& >(1-t)[P(q)-\varpi] q+(1-\widetilde{t}) \underbrace{(\varpi-c)}_{(-)} q_{I}=\Pi^{D} .
\end{aligned}
$$

Thus, the profit from dual sourcing is less than the profit under outsourcing alone simply because the foreign subsidiary that produces internally makes a loss due to the CUP method.

Proposition 3 shows that if dual sourcing triggers the CUP method, such an application of the ALP rule may fundamentally change the firm's sourcing behavior. Note that Proposition 3 does not imply that the monopolistic firm always do outsourcing when its own production cost is higher than $\varpi$. If internal sourcing makes the CUP method inapplicable, it may instead engage in internal sourcing just to avoid the imposition of the CUP method. Such a possibility is illustrated in Figure 7. The profit from outsourcing at the price of $\varpi$ can be represented by the area $(B+C)$ whereas the profit from insourcing with concealment costs can be represented by the area $(A+B)$. Thus, if area $A$ is bigger than area $C$, the insourcing will be chosen. In this case, the output decreases from $q$ to $q^{C U P}$.

We now show that when the imposition of the CUP method with dual sourcing changes sourcing behavior, the effects can be very different depending on which single sourcing method the monopolist employs. More specifically, if the imposition of the CUP method with dual sourcing induces only outsourcing, it limits tax manipulation and increases 


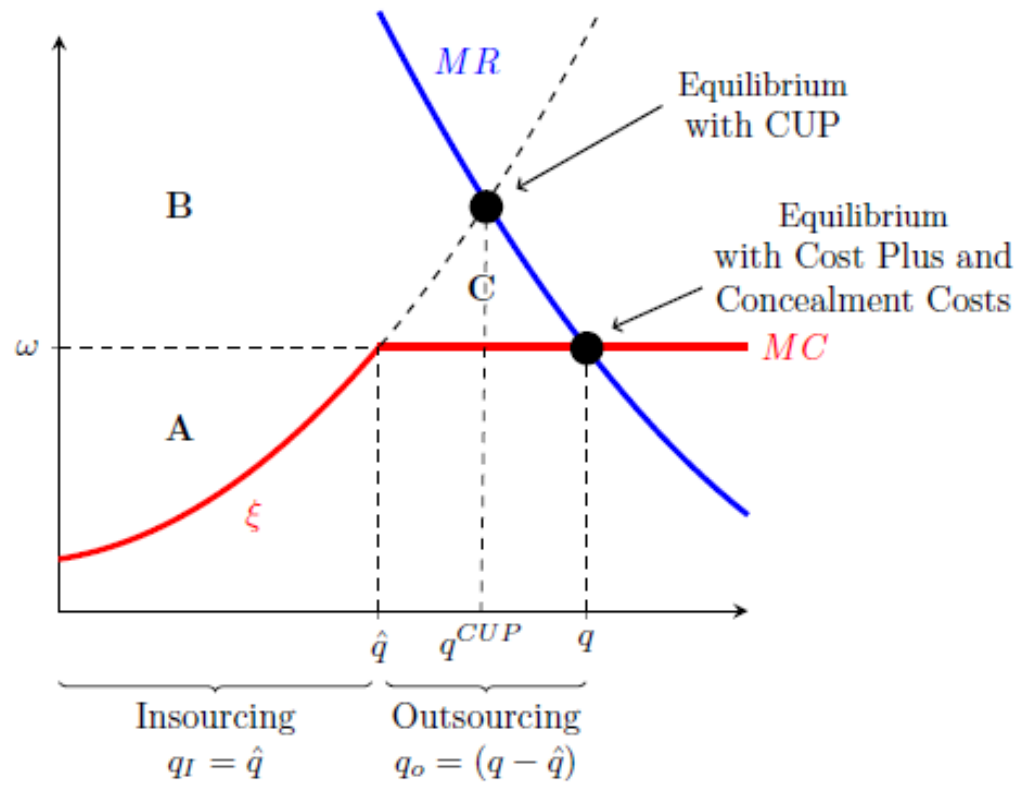

Figure 7: Sourcing Decision Change with CUP Method

tax revenues without affecting consumer surplus. However, if the imposition of the CUP method with dual sourcing induces insourcing alone, it actually reduces tax revenue and consumer surplus as well as MNE's profit. As a result, such a policy may backfire.

Proposition 4. Suppose that dual sourcing triggers the CUP method instead of the CP method with $c>\widetilde{w}$. If the MNE switches its sourcing from dual sourcing to outsourcing alone, tax revenue increases with consumer surplus unchanged. However, if insourcing alone is induced instead, both tax revenue and consumer surplus decrease.

Proof. Suppose that the home government switches the ALP method from CP to CUP when the MNE engages in dual sourcing. If the MNE switches from dual sourcing to outsourcing alone, then its $M C$ remains to be $\varpi$, implying that the output level does not change. However, the tax revenue increases, because the downstream profit increases:

$$
P(q) q-\varpi q>P(q) q-\gamma q_{I}-\varpi q_{O} .
$$

If the MNE switches from dual sourcing to insourcing alone, on the other hand, its 
output given by $q^{C U P}$ becomes smaller. In addition, we have

$$
\begin{aligned}
P(q) q-\gamma q_{I}-\varpi q_{O} & =[P(q)-w] q-(\gamma-\varpi) q_{I} \\
& \geq\left[P\left(q^{C U P}\right)-w\right] q^{C U P}-(\gamma-\varpi) q_{I} \\
& \geq\left[P\left(q^{C U P}\right)-\gamma\right] q^{C U P}+(\gamma-\varpi)\left(q^{C U P}-q_{I}\right) \\
& \geq\left[P\left(q^{C U P}\right)-\gamma\right] q^{C U P}
\end{aligned}
$$

Thus, the downstream profit also decreases.

\section{Import Tariffs as Countermeasures against Profit-Shifting}

We consider a specific industry in which the MNE is operating. Implicitly we assume that the overall corporate tax rate is determined by factors beyond the specific industry we consider. The overall corporate tax rate thus cannot be tailored for this particular industry and is considered exogenously given. However, in face of MNE's profit-shifting incentives, the government may impose industry-specific ad-valorem import tariffs to eliminate such incentives. We explore import tariffs adopted as countermeasures against profit shifting.

Let $\tau_{m}$ denote ad-valorem import tariff imposed by country $H$ where the headquarter is located. Now the MNE's problem with FDI can be written as

$$
\begin{aligned}
\widehat{\Pi} & =(1-t)\left[P(q)-\left(1+\tau_{m}\right) \gamma\right] q+(1-\widetilde{t})(\gamma-c) q-\phi(\gamma-c) q \\
& =(1-t)[P(q)-\widehat{\xi}] q
\end{aligned}
$$

where

$$
\begin{aligned}
\widehat{\xi} & =\tau_{m} \gamma+\frac{(1-\widetilde{t}) c-(t-\widetilde{t}) \gamma+\phi(\gamma-c)}{1-t} \\
& =\tau_{m} \gamma+\xi
\end{aligned}
$$

with $\xi=\frac{(1-\widetilde{t}) c-(t-\widetilde{t}) \gamma+\phi(\gamma-c)}{1-t}=c-\frac{(t-\widetilde{t})(\gamma-c)-\phi(\gamma-c)}{1-t} .{ }^{14}$

In the presence of import tariffs, the optimal choice of the transfer price $\widehat{\gamma}^{*}$ is equivalent

\footnotetext{
${ }^{14}$ We denote all variables in the presence of import tariffs with a hat $(\wedge)$
} 
to minimize the MNE's "PMC cum tariffs", $\widehat{\xi}$, and implicitly defined by

$$
(t-\widetilde{t})-\tau_{m}(1-t)=\phi^{\prime}(\widehat{\gamma}-c)
$$

Totally differentiating the first order condition above, we obtain

$$
-(1-t) d \tau_{m}=\phi^{\prime \prime}\left(\widehat{\gamma}^{*}-c\right) d \widehat{\gamma}^{*}
$$

Thus, we have

$$
\frac{\partial \widehat{\gamma}^{*}}{\partial \tau_{m}}=-\frac{(1-t)}{\phi^{\prime \prime}\left(\widehat{\gamma}^{*}-c\right)}<0
$$

indicating that the incentives to inflate the internal price by the MNE can be mitigated by an import tariff. Note that the optimal $\widehat{\gamma}^{*}$ chosen by the MNE can be written as

$$
\widehat{\gamma}^{*}=c+\phi^{\prime-1}\left((t-\widetilde{t})-\tau_{m}(1-t)\right)
$$

This implies that $\tau_{m}=\bar{\tau}_{m}\left(=\frac{t-\widetilde{t}}{1-t}\right)$ completely offsets any incentives for profit shifting. In addition, with $\tau_{m}=\bar{\tau}_{m}, \widehat{\xi}=c$ holds and the MNE will engage in FDI only when its internal production is more efficient than the open market. However, consumer welfare goes down compared to the case without import tariffs. Thus, the optimal import tariff can be lower than $\bar{\tau}_{m}$ (i.e., the import tariff that eliminates any incentives for profit shifting) as shown below.

\subsection{The Optimal Import Tariff}

Let us analyze the government's optimal choice of import tariff given $(t, \widetilde{t})$ when it maximizes domestic social welfare, $W$, which is defined as the sum of producer surplus (i.e., profit), consumer surplus and tax revenue. We consider import tariffs as a second-best policy when the transfer price and output choices are left to the firm. Let $\widehat{\xi}^{*}$ be the minimized PMC with the choice of optimal transfer price $\widehat{\gamma}^{*}$, that is,

$$
\widehat{\xi}^{*}=\tau_{m} \widehat{\gamma}^{*}+\frac{(1-\widetilde{t}) c-(t-\widetilde{t}) \widehat{\gamma}^{*}+\phi\left(\widehat{\gamma}^{*}-c\right)}{1-t} .
$$


Let the corresponding output level be $q\left(\widehat{\xi}^{*}\right)$. Then, social welfare with FDI can be written as

$$
\begin{aligned}
W= & \underbrace{(1-t)\left[P\left(q\left(\widehat{\xi}^{*}\right)\right)-\widehat{\xi}^{*}\right] q\left(\widehat{\xi}^{*}\right)}_{\text {Producer Surplus }}+\underbrace{\left[\int_{0}^{q\left(\widehat{\xi}^{*}\right)} P(x) d x-P\left(q\left(\widehat{\xi}^{*}\right)\right) q\left(\widehat{\xi}^{*}\right)\right]}_{\text {Consumer Surplus }} \\
& +\underbrace{\left[t\left[P\left(q\left(\widehat{\xi}^{*}\right)\right)-\left(1+\tau_{m}\right) \widehat{\gamma}^{*}\right] q\left(\widehat{\xi}^{*}\right)+\tau_{m} \widehat{\gamma}^{*} q\left(\widehat{\xi}^{*}\right)\right]}_{\text {Tax and Tariff Revenues }} \\
= & (1-t)\left[P\left(q\left(\widehat{\xi}^{*}\right)\right)-\left(1+\tau_{m}\right) \widehat{\gamma}^{*}\right] q\left(\widehat{\xi}^{*}\right)+(1-\widetilde{t})\left(\widehat{\gamma}^{*}-c\right) q\left(\widehat{\xi}^{*}\right)-\phi\left(\widehat{\gamma}^{*}-c\right) q\left(\widehat{\xi}^{*}\right) \\
& +\left[\int_{0}^{q\left(\widehat{\xi}^{*}\right)} P(x) d x-P\left(q\left(\widehat{\xi}^{*}\right)\right) q\left(\widehat{\xi}^{*}\right)\right]+\left[t\left[P\left(q\left(\widehat{\xi}^{*}\right)\right)-\left(1+\tau_{m}\right) \widehat{\gamma}^{*}\right] q\left(\widehat{\xi}^{*}\right)+\tau_{m} \widehat{\gamma}^{*} q\left(\widehat{\xi}^{*}\right)\right]
\end{aligned}
$$

Collecting terms, we can write social welfare in a more compact form as follows:

$$
W=\int_{0}^{q\left(\widehat{\xi}^{*}\right)}\left[P(x)-\widehat{\xi}^{S P}\right] d x
$$

where $\widehat{\xi}^{S P}=c+\widetilde{t}\left(\widehat{\gamma}^{*}-c\right)+\phi\left(\widehat{\gamma}^{*}-c\right)$ and represents the MC of FDI production from the perspective of the social planner of country $H$. It consists of the physical production cost of $c$, tax transfer to the host country, and any concealment costs incurred by the MNE. Note that the MNE's production level is determined not by the social planner's MC, $\widehat{\xi}^{S P}$, but by its PMC, $\widehat{\xi}^{*}$. This implies that the choice of $\tau_{m}$ that minimizes $\widehat{\xi}^{S P}$ is not necessarily the optimal import tariff.

It is instructive to investigate the relationship between PMC and social cost associated with transfer pricing as the import tariff changes. To this end, let us define the wedge between the MNE's PMC and the social planner's MC as $\delta=\widehat{\xi}\left(\gamma\left(\tau_{m}\right)\right)-\widehat{\xi}^{S P}\left(\gamma\left(\tau_{m}\right)\right)$. Then, we have

$$
\widehat{\xi}\left(\gamma\left(\tau_{m}\right)\right)-\widehat{\xi}^{S P}\left(\gamma\left(\tau_{m}\right)\right)=\tau_{m} \gamma+\frac{t}{1-t}[\phi(\gamma-c)-(1-\widetilde{t})(\gamma-c)],
$$

where $\widehat{\gamma}^{*}=c+\phi^{\prime-1}\left((t-\widetilde{t})-\tau_{m}(1-t)\right)$.

Since $\gamma=c$ when $\tau_{m}=\frac{t-\widetilde{t}}{1-t}$, we have

$$
\left.\delta\right|_{\tau_{m}=\frac{t-\tilde{t}}{1-t}}=\widehat{\xi}(\gamma)-\left.\widehat{\xi}^{S P}(\gamma)\right|_{\tau_{m}=\frac{t-\tilde{t}}{1-t}}=\frac{t-\widetilde{t}}{1-t} c>0 .
$$


We can also easily verify that

$$
\left.\delta\right|_{\tau_{m}=0}=\widehat{\xi}(\gamma)-\left.\widehat{\xi}^{S P}(\gamma)\right|_{\tau_{m}=0}=\left.\frac{t}{1-t}[\phi(\gamma-c)-(1-\widetilde{t})(\gamma-c)]\right|_{\tau_{m}=0}<0 .
$$

To see this, note that $\gamma$ satisfies the first order condition $(t-\widetilde{t})=\phi^{\prime}(\gamma-c)$. Since $\phi$ is convex, we have

$$
\frac{\phi(\gamma-c)}{\gamma-c}<\phi^{\prime}(\gamma-c)=(t-\widetilde{t})<1-\widetilde{t}
$$

Thus, $(1-\widetilde{t})(\gamma-c)>\phi(\gamma-c)$. We also know that

$$
\frac{d\left[\widehat{\xi}\left(\gamma\left(\tau_{m}\right)\right)-\widehat{\xi}^{S P}\left(\gamma\left(\tau_{m}\right)\right)\right]}{d \tau_{m}}=\gamma-\left[\widetilde{t}+\phi^{\prime}(\gamma-c)\right] \frac{\partial \widehat{\gamma}}{\partial \tau_{m}}>0
$$

because $\phi^{\prime}(\gamma-c)>0$ and $\frac{\partial \widehat{\gamma}}{\partial \tau_{m}}<0$. Thus, we obtain the following lemma.

Lemma 2. There is a unique $\tau_{m}^{o} \in\left(0, \frac{t-\widetilde{t}}{1-t}\right)$ such that

$$
\left\{\begin{array}{l}
\widehat{\xi}(\gamma)<\widehat{\xi}^{S P}(\gamma) \text { if } \tau_{m}<\tau_{m}^{o} \\
\widehat{\xi}(\gamma)=\widehat{\xi}^{S P}(\gamma) \text { if } \tau_{m}=\tau_{m}^{o} \\
\widehat{\xi}(\gamma)>\widehat{\xi}^{S P}(\gamma) \text { if } \tau_{m}>\tau_{m}^{o}
\end{array}\right.
$$

Lemma 2 implies that if $\tau_{m} \geq \tau_{m}^{o}$, the output level by the MNE is unambiguously too low from the social planner's viewpoint. When $\tau_{m}=\tau_{m}^{o}$, the PMC and social planner's cost coincide, but due to the exercise of monopoly power, the output is still too low. If $\tau_{m}>\tau_{m}^{o}$, the output is further restricted because PMC exceeds the social MC. This concern may induce the social planner to set an import tariff lower than $\tau_{m}^{o}$ and we derive such conditions below.

Now let us analyze the marginal effect of an import tariff on social welfare:

$$
\frac{d W}{d \tau_{m}}=\left[P\left(q\left(\tau_{m}\right)\right)-\widehat{\xi}^{S P}\left(\tau_{m}\right)\right] \underbrace{\frac{d q\left(\tau_{m}\right)}{d \tau_{m}}}_{(-)}+[-q\left(\tau_{m}\right) \underbrace{\frac{d \widehat{\xi}^{S P}}{d \tau_{m}}}_{(-)}]
$$


where

$$
\begin{aligned}
\frac{d q\left(\tau_{m}\right)}{d \tau_{m}} & =\frac{d q}{d \widehat{\xi}}[\frac{\partial \widehat{\xi}^{*}}{\partial \tau_{m}}+\underbrace{\frac{\partial \widehat{\xi}^{*}}{\partial \widehat{\gamma} \frac{\partial \widehat{\gamma}^{*}}{\partial \tau_{m}}}}_{=0}]=\underbrace{\frac{d q}{d \widehat{\xi}}}_{(-)} \widehat{\gamma}^{*}<0 \\
\text { and } \frac{d \widehat{\xi}^{S P}}{d \tau_{m}} & =\frac{\partial \widehat{\xi}^{S P}(\widehat{\gamma})}{\partial \widehat{\gamma}} \frac{\partial \widehat{\gamma}^{*}}{\partial \tau_{m}}=[\underbrace{\tilde{t}+\phi^{\prime}\left(\widehat{\gamma}^{*}-c\right)}_{(+)}] \frac{\partial \widehat{\gamma}^{*}}{\partial \tau_{m}}<0 .
\end{aligned}
$$

Equation (5) illustrates the trade-offs involved in setting an import tariff. The first term on the RHS represents the negative effect on consumer welfare as the imposition of import tariffs increases the MNE's PMC which induces the firm to reduce outputs in the domestic market. The second term on the RHS is the positive effect of reducing tax shifting to country $F$ and concealment costs.

It is clearly not optimal to set an import tariff higher than $\bar{\tau}_{m}=\frac{t-\widetilde{t}}{1-t}$ because it is simply an overkill as countermeasures against profit shifting: an import tariff beyond $\bar{\tau}_{m}$ only reduces consumer welfare without any corresponding positive benefits in terms of social welfare. We thus consider only import tariffs with $\tau_{m} \leq \bar{\tau}_{m}$.

A sufficient condition for the optimal import tariff to be less than $\bar{\tau}_{m}$ is

$$
\left.\frac{d W}{d \tau_{m}}\right|_{\tau_{m}=\bar{\tau}_{m}}=\left.\frac{d}{d \tau_{m}}\left[\int_{0}^{q(\widehat{\xi}(\gamma))} P(x)-\widehat{\xi}^{S P}(\gamma) d x\right]\right|_{\tau_{m}=\frac{t-\tilde{t}}{1-t}}<0 .
$$

The following proposition provides a sufficient condition for this.

Proposition 5. Let $\rho=P^{\prime} \frac{d q}{d \xi}$ denote the cost-price pass-through rate for the monopolist. $\left.\frac{d W}{d \tau_{m}}\right|_{\tau_{m}=\bar{\tau}_{m}}<0$ if $\rho>\left.\frac{\left|\frac{d \hat{\xi}^{S P}}{d \tau m}\right|}{\frac{d \xi}{d \tau_{m}}}\right|_{\tau_{m}=\frac{t-\tilde{t}}{1-t}}$.

Proof. We have

$$
\begin{aligned}
\frac{d W}{d \tau_{m}} & =\left[P\left(q\left(\tau_{m}\right)\right)-\widehat{\xi}^{S P}\left(\tau_{m}\right)\right] \underbrace{\frac{d q\left(\tau_{m}\right)}{d \tau_{m}}}_{(-)}-q\left(\tau_{m}\right) \underbrace{\frac{\widehat{d \xi}^{S P}}{d \tau_{m}}}_{(+)} \\
& =\left[P\left(q\left(\tau_{m}\right)\right)-\widehat{\xi}^{*}+\left(\widehat{\xi}^{*}-\widehat{\xi}^{S P}\left(\tau_{m}\right)\right)\right] \frac{d q\left(\tau_{m}\right)}{d \tau_{m}}-q\left(\tau_{m}\right) \frac{d \widehat{\xi}^{S P}}{d \tau_{m}}
\end{aligned}
$$


By Lemma 2, we know $\widehat{\xi}^{*}-\widehat{\xi}^{S P}>0$ at $\tau_{m}=\bar{\tau}_{m}$. In addition, we know that

$$
P\left(q\left(\tau_{m}\right)\right)-\widehat{\xi}^{*}=-P^{\prime} q
$$

by the first order condition for the MNE's profit maximization and $\frac{d q\left(\tau_{m}\right)}{d \tau_{m}}<0$. As a result, we have

$$
\begin{aligned}
\left.\frac{d W}{d \tau_{m}}\right|_{\tau_{m}=\bar{\tau}_{m}} & <-P^{\prime} q \frac{d q\left(\tau_{m}\right)}{d \tau_{m}}-\left.q\left(\tau_{m}\right) \frac{d \widehat{d \xi}^{S P}}{d \tau_{m}}\right|_{\tau_{m}=\frac{t-\tilde{t}}{1-t}} \\
& =-\left.q\left[P^{\prime} \frac{d q}{d \xi} \frac{d \xi}{d \tau_{m}}+\frac{d \widehat{\xi}^{S P}}{d \tau_{m}}\right]\right|_{\tau_{m}=\frac{t-\tilde{t}}{1-t}}
\end{aligned}
$$

Therefore,

$$
\left.\frac{d W}{d \tau_{m}}\right|_{\tau_{m}=\bar{\tau}_{m}}<-\left.q\left[P^{\prime} \frac{d q}{d \xi} \frac{d \xi}{d \tau_{m}}+\frac{\widehat{d \vec{\xi}}^{S P}}{d \tau_{m}}\right]\right|_{\tau_{m}=\frac{t-\tilde{t}}{1-t}}<0 \text { if } \rho>\left.\frac{\left|\frac{d \widehat{\xi}^{S P}}{d \tau_{m}}\right|}{\frac{d \xi}{d \tau_{m}}}\right|_{\tau_{m}=\frac{t-\tilde{t}}{1-t}}
$$

Thus, we can conclude that the optimal import tariff $\tau_{m}^{*}<\bar{\tau}_{m}=\frac{t-\widetilde{t}}{1-t}$, that is, the optimal import tariff mitigates incentives to engage in tax manipulation via transfer price, but does not completely eliminate it, if $\rho>\left.\frac{\left|\frac{d \widehat{\xi}^{S P}}{d \tau_{m}}\right|}{\frac{d \xi}{d \tau_{m}}}\right|_{\tau_{m}=\bar{\tau}_{m}}$. This is because the transfer price induces the MNE to produce more, which enhances consumer welfare. For instance, this condition is satisfied if $\widetilde{t}$ is sufficiently small because $\left|\frac{d \widehat{\xi}^{S P}}{d \tau_{m}}\right|_{\tau_{m}=\bar{\tau}_{m}}=\widetilde{t} \frac{(1-t)}{\phi^{\prime \prime}\left(\widehat{\gamma}^{*}-c\right)} \simeq 0$ and $\left.\frac{d \xi}{d \tau_{m}}\right|_{\tau_{m}=\bar{\tau}_{m}}=c$.

Without imposing further structures on the model, it is difficult to further characterize the optimal tariff. However, if we assume a constant cost pass-through rate and a quadratic function in the concealment cost specification, we can derive conditions under which the optimal import rate is lower than $\tau_{m}^{o} \cdot{ }^{15}$

Proposition 6. Let $\rho$ be the constant cost pass-through rate. If $\rho>\left.\frac{\left|\frac{d \widehat{\xi}^{S P}}{d \tau_{m}}\right|}{\frac{d \xi}{d \tau_{m}}}\right|_{\tau_{m}=\tau_{m}^{o}}$ and $\phi$ is quadratic, we have $\tau_{m}^{*}<\tau_{m}^{o}$.

Proof. See the Appendix.

\footnotetext{
${ }^{15}$ For instance, constant elasticity demand curves and linear demand curves have a constant cost passthrough rate. See Bulow and Pfleiderer (1983) and Weyl and Fabinger (2013).
} 


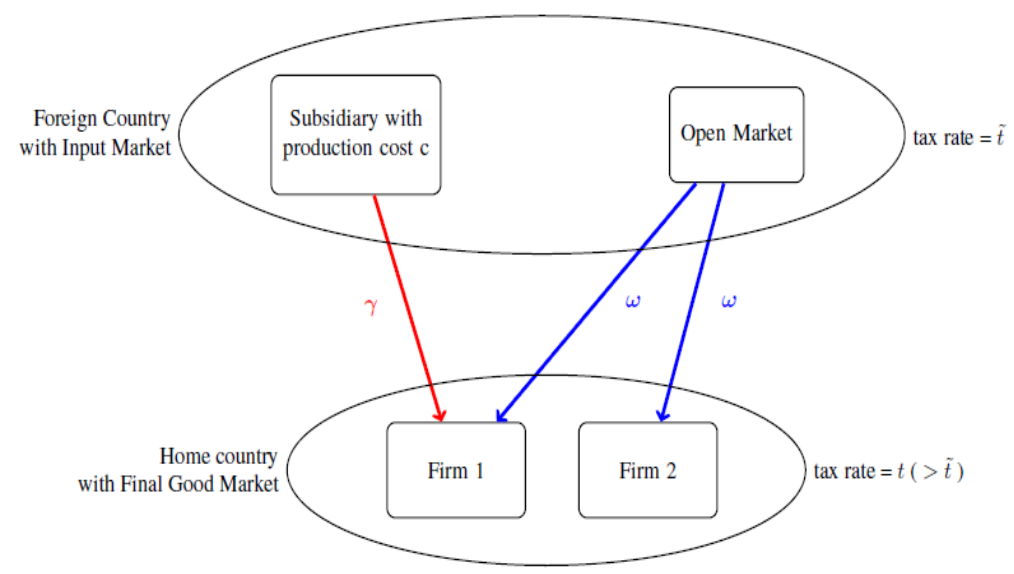

Figure 8: Duopoly Model with Strategic Interactions

The logic of the proof is similar to the one for Proposition 5. The condition that $\phi$ is quadratic ensures that $\left|\frac{d \widehat{\xi}^{S P}}{d \tau_{m}}\right| / \frac{d \xi}{d \tau_{m}}$ is decreasing in $\tau_{m}$. Thus, when the pass-through rate is constant, the condition guarantees that $\frac{d W}{d \tau_{m}}<0$ for all $\tau_{m} \geq \tau_{m}^{o}$.

\section{The Duopoly Model with Strategic Interactions}

In this section we consider a duopoly model in which an MNE competes with another downstream firm in Home in order to explore implications of strategic effects. The set-up is otherwise the same as in the monopoly model. More specifically, two final-good producers, firm 1 and firm 2, compete in Home. Firm 2 is a home firm and simply procures its input from Foreign with an exogenously given market price $\widetilde{\gamma}=\varpi$ (in section 4 , we extend the model to endogenize $\widetilde{\gamma}$ ). Firm 1 has two sourcing choices as before. It can procure its input from Foreign like firm 2. Alternatively, it can set up its own input-production plant in Foreign. In this case, the MC of input production is given by $c$. The MNE chooses an internal transfer price, $\gamma$, when its foreign subsidiary supplies its input to the headquarters that produces the final good. Figure 8 illustrates the duopoly model.

In the monopoly case, we assumed that the CUP method is not applicable, because there is no comparable downstream firm and the input market simply does not exist in the case of FDI (unless the MNE is engaged in dual sourcing that also relies on outside suppliers). As a result, the ALP was based on the CP method and the MNE was assumed to incur concealment costs when its transfer price deviates from its MC. In the 
duopoly case, the applicability of the CUP method depends on whether the transactions between the rival downstream firm and its input suppliers can be regarded as "externally comparable" to internal transactions of the MNE (OECD 2010, p. 71).

We present two sets of results depending on the comparability of the external transactions. In section 3.1, we first consider a scenario in which the external transactions are not considered as comparable. This would be the case if the two downstream firms produce differentiated products and use different types of inputs. Then, the ALP should be based on the CP method and the MNE operates with concealment costs. In contrast, if the external transactions are considered as comparable, then the MNE is constrained to use the comparable market price $(\varpi)$ as the internal transfer price. This second scenario is analyzed in section 3.2 .

\subsection{The CP Method: Non-Comparable External Transactions}

We first analyze the case in which the transactions between the rival downstream firm and its input suppliers are not comparable to the internal transactions of the MNE. In this case, the MNE's behavior can be described with the presence of concealment costs for transfer price that deviates from its true MC, as in the monopoly case. We maintain the assumption that concealment costs are linear in output, that is, $\Phi(\gamma-c, q)=\phi(\gamma-c) q$ with $\phi^{\prime}>0, \phi^{\prime \prime}>0$ with $\phi^{\prime}(0)=0$.

To obtain the implications of strategic interactions for the MNE's behavior, we assume that in the downstream market, the two firms compete in quantities with the standard assumption of strategic substitutes. More specifically, let $P_{i}\left(q_{1}, q_{2}\right)$ denote firm $i$ 's price when firm 1 and firm 2 produce $q_{1}$ and $q_{2}$, respectively.

Firm 1 solves the following problem:

$$
\underset{q_{1}}{\operatorname{Max}} \Pi_{1}=(1-t) \underbrace{\left[P_{1}\left(q_{1}, q_{2}\right)-\gamma\right] q_{1}}_{\text {Downstream Profits }}+(1-\widetilde{t}) \underbrace{(\gamma-c) q_{1}}_{\text {Upstream Profits }}-\underbrace{\phi(\gamma-c) q_{1}}_{\text {Concealment Costs }} .
$$

Once again, by collecting terms with $q_{1}$, we can rewrite it as

$$
\Pi_{1}=(1-t)\left[P_{1}\left(q_{1}, q_{2}\right)-\xi\right] q_{1},
$$

where

$$
\xi \equiv \frac{(1-\widetilde{t}) c-(t-\widetilde{t}) \gamma+\phi(\gamma-c)}{1-t}
$$


The FOC for firm 1 is given by

$$
\frac{1}{1-t} \frac{\partial \Pi_{1}}{\partial q_{1}}=\frac{\partial \pi_{1}\left(q_{1}, q_{2} ; \xi\right)}{\partial q_{1}}=0
$$

Firm 2 similarly makes its decision on $q_{2}$ to solve the following problem:

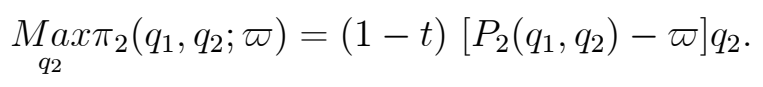

The FOC is

$$
\frac{\partial \pi_{2}\left(q_{1}, q_{2} ; \varpi\right)}{\partial q_{2}}=0
$$

Given a transfer price $\gamma$, the FOCs (6) and (7) implicitly define reaction functions for firm 1 and firm 2, respectively. The equilibrium quantities for each firm, $q_{1}^{*}(\xi, \varpi)$ and $q_{2}^{*}(\xi, \varpi)$ are at the intersection of these two reaction functions, given the transfer price $\gamma$.

Assume $\left|\frac{\partial^{2} \pi_{i}}{\partial q_{i}^{2}}\right|>\left|\frac{\partial^{2} \pi_{i}}{\partial q_{i} \partial q_{j}}\right|$, where $i=1,2$ and $j \neq i$. Then, we have the following standard result.

Lemma 3. $\frac{\partial q_{1}^{*}(\xi, \varpi)}{\partial \xi}<0$ and $\frac{\partial q_{2}^{*}(\xi, \varpi)}{\partial \xi}>0$.

Proof. See the Appendix.

Let $\pi_{i}^{*}(\xi, \varpi)$ denote the equilibrium profit of firm $i$ when the MCs for firm 1 and firm 2 are given by $\xi$ and $\varpi$, respectively. Lemma 2 then immediately implies that

$$
\begin{aligned}
\frac{d \pi_{1}^{*}(\xi, \varpi)}{d \xi} & =\frac{\partial \pi_{1}}{\partial \xi}+\frac{\partial \pi_{1}}{\partial q_{2}} \frac{\partial q_{2}^{*}(\xi, \varpi)}{\partial \xi}=-q_{1}^{*}(\xi, \varpi)+\frac{\partial P_{1}}{\partial q_{2}} q_{1}^{*}(\xi, \varpi) \frac{\partial q_{2}^{*}(\xi, \varpi)}{\partial \xi}<0, \\
\frac{d \pi_{2}^{*}(\xi, \varpi)}{d \xi} & =\frac{\partial \pi_{2}}{\partial q_{1}} \frac{\partial q_{1}^{*}(\xi, \varpi)}{\partial \xi}=\frac{\partial P_{2}}{\partial q_{1}} q_{2}^{*}(\xi, \varpi) \frac{\partial q_{1}^{*}(\xi, \varpi)}{\partial \xi}>0 .
\end{aligned}
$$

That is, the equilibrium profit of each firm is decreasing in its own $\mathrm{MC}$ and increasing in its rival's MC.

Since we can write firm 1's equilibrium profit after tax as $\Pi_{1}=(1-t) \pi_{1}^{*}(\xi, \varpi)$ and $\pi_{1}^{*}(\xi, \varpi)$ is decreasing in $\xi$, the optimal choice of transfer price is equivalent to the choice of $\gamma$ that minimizes $\xi$, as in the monopoly case. When the rival firm's input is not considered comparable and the CP method is used as a regulatory policy, we replicate the same result as in the monopoly case.

We compare the case with transfer pricing regulated by the CP method against the case without transfer pricing. The use of artificially inflated internal price is used to shift 
its profit at the downstream stage to the upstream subsidiary in Foreign (the low-tax country). As a result, the tax revenue from the MNE is reduced in Home. However, it is not the end of the story; there is a collateral damage due to spillover effects. The aggressive behavior of the MNE with transfer pricing also reduces the rival's profit. Thus, the tax revenue from the other firm that is not engaged in tax manipulation also decreases (even though consumer surplus increases by transfer pricing). In other words, we uncover an additional tax-revenue loss from other firms in the presence of imperfect competition due to strategic effects.

Two remarks are in order. First, it is also possible to compare transfer pricing with and without the CP method as in the monopoly case. The introduction of the CP method in the presence of transfer pricing harms the MNE and consumers but increases tax revenue from both firms 1 and 2 .

Second, there exists a crucial difference between the strategic effects driven by tax differences in our model and strategic transfer pricing in the IO and management literature (see, for example, Alles and Datar, 1998). The basic premise of strategic transfer pricing in oligopoly models is to assume decentralized decision making and each division maximizes its own profits, rather than the overall profits of the firm. Otherwise, the optimal decisions would be based on true MCs and the transfer prices would not matter and would not generate any strategic effects, because internal transfer prices are just transfers among divisions within the firm and cancel out each other from the perspective of firm's overall profits. Only when the decision of each division is driven by its own profit, transfer price can have any meaningful effects. In contrast, our model assumes centralized decision making; besides the headquarters (the downstream division) and its subsidiary (the upstream division) are located in the different countries with deferent tax rates. If the transfer price is inflated to reduce the tax burden without centralized decision, the strategic effects will work the other way around.

\subsection{The CUP Method: Comparable External Transactions}

We now consider a scenario in which the transactions between the rival downstream firm and its input suppliers can be considered comparable. In this case, the ALP can be applied with the CUP method, which requires that the transfer price be equal to similar input price in the market, i.e., the input price paid by firm $2 .{ }^{16}$

\footnotetext{
${ }^{16}$ Gresik and Osmundsen (2008) analyze the ALP when all firms are vertically integrated and comparable but independent transactions, on which the application of the ALP can be based, is not available.
} 
If the input market for firm 2 is perfectly competitive at the price of $\varpi$, the analysis with the CUP method is straightforward. As its transfer price is constrained to be at $\varpi$ with the CUP method, firm 1 will engage in FDI if and only if FDI is efficient from the point of global efficiency, that is, $c<\varpi$. In this case, profit-shifting will take place to some extent, but it is limited by the competitive market price $\varpi$. If $c>\varpi$, there is no inefficient FDI for the profit-shifting purpose.

If we assume that the input available in the open market is supplied by a firm with market power, strategic interactions between the MNE and the foreign input supplier with market power restore various inefficient outcomes, as shown in the next section.

\section{The Duopoly Model: "Imperfect" Input Market with the CUP Method}

We now consider a case where the transactions between the rival downstream firm and its input supplier can be considered "comparable", but the foreign input market is imperfect and thus the external reference price under the CUP method cannot be treated as an exogenous parameter. More specifically, we assume that there is a single foreign input supplier with market power. The foreign input supplier behaves as a monopolist either if FDI is absent or if the MNE does not supply the input to the rival downstream firm (i.e., firm 2). It should be noted that we allow the MNE's subsidiary to supply its input to the downstream competitor if it chooses so.

With the CUP method, the transfer price with in the MNE, $\widetilde{\gamma}$, must be equal to CUP, that is, the price charged by the foreign input supplier. The dependence of the MNE's internal price on CUP creates novel strategic effects when CUP is endogenously determined. More specifically, inefficient FDI is restored in the presence of internal sourcing for tax manipulation; besides, there could be an inefficient refusal to sell to the competing downstream firm when the MNE's upstream subsidiary is more efficient than the foreign supplier. This outcome results from the incentive for tax manipulation and departs from the standard rationale for market foreclosure based on raising rival's costs in the IO literature (Salop and Scheffman, 1983; Ordover et al., 1992).

We assume the following timing for the analysis. Let $c$ and $\widetilde{c}$ be the respective constant MCs of input production for the MNE and the foreign supplier. Given $(c, \widetilde{c})$, which is

Such a issue does not arise in our model because the rival downstream firm acquires its input from an independent source. 
assumed to be common knowledge for industry participants, but unknown to the regulator, firm 1 decides whether to engage in FDI. If it sets up an upstream subsidiary, it procures its input internally and at the same time sets a price at which it commits to supply to its downstream rival, i.e., firm 2. The internal transfer price is determined by the input acquisition price of the downstream rival under the CUP method. Given the input price commitment by the MNE, the foreign input supplier sets its own price. The downstream rival acquires its input from the input supplier with the lower price. If firm 1 does not set up an upstream subsidiary, the foreign supplier sets the monopoly price to sell to both downstream firms.

We should mention that this timing assumption is equivalent to a dynamic negotiating process in which the price stage game is modeled as a descending price auction in which the MNE's subsidiary and the foreign supplier are bidders (see Reiffen, 1992; Ordover et al. 1992$) \cdot{ }^{17}$

The equilibrium outcomes in this setting have different characterizations depending on the relative efficiency of the MNE's subsidiary, $c$, and the foreign input supplier, $\widetilde{c}$. In the following, we consider two cases: $c>\widetilde{c}$ and $c<\widetilde{c}$.

\subsection{The Case with $c>\widetilde{c}$ : Inefficient FDI}

We first analyze the case in which the MNE is less efficient than the foreign supplier, i.e., $c>\widetilde{c}$. We show that FDI arises even if $c>\widetilde{c}$. Again, such FDI is inefficient from the viewpoint of the global production.

With $c>\widetilde{c}$, any input price $(\geq \widetilde{c})$ set by the MNE will be undercut by the foreign supplier. This means that it is a weakly dominant strategy for the MNE's subsidiary to set a price very high (which is equivalent to the MNE's refusal to sell to firm 2). Under the CUP method, firm 1 behaves as if its input cost were

$$
\xi^{C U P}(\widetilde{\gamma}) \equiv \frac{(1-\widetilde{t}) c-(t-\widetilde{t}) \widetilde{\gamma}}{1-t}
$$

if the foreign supplier sets a price of $\widetilde{\gamma}$. Let $q(x, y)$ denote the equilibrium output level for a downstream firm when its input cost is $x$ while the rival firm's cost is given by $y$.

\footnotetext{
${ }^{17}$ We adopt this particular assumption to facilitate comparison of our results to the standard IO foreclosure literature. We can derive a similar set of results with different timing assumptions. For instance, we can obtain similar results if the foreign supplier sets its input price first and firm 1 can decide whether or not to engage in FDI after observing the input price.
} 
If firm 1 sets up a subsidiary and does internal sourcing, firm 2's input demand at price $\widetilde{\gamma}$ can be written as

$$
q_{2}^{C U P}(\widetilde{\gamma})=q\left(\widetilde{\gamma}, \xi^{C U P}(\widetilde{\gamma})\right)
$$

The input demand expression above indicates that there are two channels through which the foreign supplier's price affects firm 2's demand. First, firm 2's input demand is directly affected by the price it pays to the foreign supplier. Second, there is an indirect effect through the PMC of firm 1 because firm 1's transfer price is determined by the price firm 2 pays to the foreign supplier under the CUP method. The foreign input supplier thus faces the following problem:

$$
\operatorname{Max}_{\widetilde{\gamma}}^{m}=(\widetilde{\gamma}-\widetilde{c}) q\left(\widetilde{\gamma}, \xi^{C U P}(\widetilde{\gamma})\right) .
$$

In contrast, if firm 1 does outsourcing from the foreign input supplier, the foreign input supplier sets its input price to maximize

$$
\pi_{b}^{m}=(\widetilde{\gamma}-\widetilde{c}) 2 q(\widetilde{\gamma}, \widetilde{\gamma})
$$

For analytical simplicity, let us assume that both $\pi_{2}^{m}$ and $\pi_{b}^{m}$ are concave in $\widetilde{\gamma}$.

Let us consider the case of FDI by firm 1 . Then, the FOC for the foreign supplier is given by

$$
\frac{\partial \pi_{2}^{m}}{\partial \widetilde{\gamma}}=q\left(\widetilde{\gamma}, \xi^{C U P}\right)+(\widetilde{\gamma}-\widetilde{c})[\underbrace{\frac{\partial q}{\partial x}}_{\text {Direct Effect (-) }}+\underbrace{\frac{\partial q}{\partial y} \frac{\partial \xi^{C U P}}{\partial \widetilde{\gamma}}}_{\text {Indirect Effect via Transfer Pricing (-) }}]=0 .
$$

Thus, the optimal price, $\widetilde{\gamma}^{*}$, is implicitly defined by

$$
\widetilde{\gamma}^{*}=\widetilde{c}-\frac{q\left(\widetilde{\gamma}^{*}, \xi^{C U P}\right)}{\left[\frac{\partial q}{\partial x}+\frac{\partial q}{\partial y} \frac{\partial \xi^{C U P}}{\partial \widetilde{\gamma}}\right]}>\widetilde{c} .
$$

With the CUP method applied as the ALP, the input price of the foreign supplier, $\widetilde{\gamma}$, influences the MNE's transfer price and indirectly affects MNE's competitive behavior in the downstream market via its effect on $\xi^{C U P}$. Since $\frac{\partial \xi^{C U P}}{\partial \widetilde{\gamma}}=\frac{-(t-\widetilde{t})}{1-t}<0$, a higher input price to firm 2 decreases firm 1's PMC $\left(\xi^{C U P}\right)$ and indirectly reduces firm 2's output because of strategic effects via transfer pricing. Thus, if firm 1 produces its input 
internally with FDI, the foreign supplier charges a lower input price under the CUP method compared to the case in which such an indirect channel is absent.

To reduce the number of cases to consider, we assume that the gap between $\widetilde{c}$ and $c$ is not too large. More specifically, we assume

$$
\left.\frac{\partial \pi_{2}^{m}}{\partial \widetilde{\gamma}}\right|_{\widetilde{\gamma}=c}=q(c, c)+(c-\widetilde{c})\left(\frac{\partial q(c, c)}{\partial x}-\frac{\partial q(c, c)}{\partial y} \frac{(t-\widetilde{t})}{1-t}\right)>0,
$$

that is,

$$
(c-\widetilde{c})<\frac{q(c, c)}{\left|\frac{\partial q(c, c)}{\partial x}-\frac{\partial q(c, c)}{\partial y} \frac{(t-\widetilde{t})}{1-t}\right|} .
$$

This condition guarantees that the input price for the downstream rival (i.e., firm 2) in the presence of FDI, denoted as $\widetilde{\gamma}^{*}$, is higher than $c$.

To analyze the incentive for firm 1 to set up a foreign subsidiary, let us analyze the input price in the absence of FDI. The FOC for the optimal input price without FDI, denoted by $\widetilde{\gamma}^{* *}$, is given by

$$
\frac{\partial \pi_{b}^{m}}{\partial \widetilde{\gamma}}=2\left[q(\widetilde{\gamma}, \widetilde{\gamma})+(\widetilde{\gamma}-\widetilde{c})\left(\frac{\partial q(\widetilde{\gamma}, \widetilde{\gamma})}{\partial x}+\frac{\partial q(\widetilde{\gamma}, \widetilde{\gamma})}{\partial y}\right)\right]=0 .
$$

Then, we obtain the following lemma.

Lemma 4. Under condition (9), $\widetilde{\gamma}^{* *}>\widetilde{\gamma}^{*}$.

Proof. Note that under condition (9), $\widetilde{\gamma}^{*}>c$ and we have

$$
\xi^{C U P}\left(\widetilde{\gamma}^{*}\right)=\frac{(1-\widetilde{t}) c-(t-\widetilde{t}) \widetilde{\gamma}^{*}}{1-t}<c
$$

Thus, $\xi^{C U P}\left(\widetilde{\gamma}^{*}\right)<\widetilde{\gamma}^{*}$. This implies that $q\left(\widetilde{\gamma}^{*}, \widetilde{\gamma}^{*}\right)>q\left(\widetilde{\gamma}^{*}, \xi^{C U P}\left(\widetilde{\gamma}^{*}\right)\right)$. We can evaluate the FOC for $\widetilde{\gamma}^{* *}$ at $\widetilde{\gamma}=\widetilde{\gamma}^{*}$ :

$$
\begin{aligned}
\left.\frac{1}{2} \frac{\partial \pi_{b}^{m}}{\partial \widetilde{\gamma}}\right|_{\widetilde{\gamma}=\widetilde{\gamma}^{*}} & =q\left(\widetilde{\gamma}^{*}, \widetilde{\gamma}^{*}\right)+\left(\widetilde{\gamma}^{*}-\widetilde{c}\right)\left(\frac{\partial q}{\partial x}+\frac{\partial q}{\partial y}\right) \\
& >q\left(\widetilde{\gamma}^{*}, \xi^{C U P}\left(\widetilde{\gamma}^{*}\right)\right)+\left(\widetilde{\gamma}^{*}-\widetilde{c}\right)\left(\frac{\partial q}{\partial x}-\frac{\partial q}{\partial y} \frac{(t-\widetilde{t})}{1-t}\right)=\left.\frac{\partial \pi_{2}^{m}}{\partial \widetilde{\gamma}}\right|_{\widetilde{\gamma}=\widetilde{\gamma}^{*}}=0
\end{aligned}
$$

Thus, $\widetilde{\gamma}^{* *}>\widetilde{\gamma}^{*}$. 
The intuition for the lemma above can be explained by the dependence of the MNE's internal price on the price set by the foreign input supplier. As the MNE's internal price is inversely related to the price, the foreign supplier has less incentive to increase its price when FDI is present and the internal price is regulated to be equal to CUP.

The following proposition is established regarding firm 1's incentive for FDI.

Proposition 7. Under condition (9), firm 1 engages in FDI even if $c>\widetilde{c}$.

Proof. We consider firm 1's FDI incentive. The equilibrium profit for firm 1 in the absence of FDI is given by $\pi^{*}\left(\widetilde{\gamma}^{* *}, \widetilde{\gamma}^{* *}\right)$ whereas its profit under FDI is given by $\pi^{*}\left(\xi^{C U P}\left(\widetilde{\gamma}^{*}\right), \widetilde{\gamma}^{*}\right)$. By lemma 3, we have $\widetilde{\gamma}^{* *}>\widetilde{\gamma}^{*}>c>\xi^{C U P}\left(\widetilde{\gamma}^{*}\right)$. As a result, we have

$$
\underbrace{\pi^{*}\left(\xi^{C U P}\left(\widetilde{\gamma}^{*}\right), \widetilde{\gamma}^{*}\right)}_{\text {Profit with FDI }}>\pi^{*}\left(\widetilde{\gamma}^{*}, \widetilde{\gamma}^{*}\right)>\underbrace{\pi^{*}\left(\widetilde{\gamma}^{* *}, \widetilde{\gamma}^{* *}\right)}_{\text {Profit without FDI }}
$$

With imperfect input market, there are three factors that affect firm 1's incentive for FDI. First, there exists the profit-shifting motive which facilitates FDI. Second, FDI enables firm 1 to avoid the exercise of market power by the foreign input supplier. Lastly, FDI results in a lower input price for the rival downstream firm under the CUP method, which discourages FDI. Taken together, Proposition 5 shows that the first two effects dominate the third one unless the MNE is sufficiently inefficient compared to the foreign supplier.

\subsection{The Case with $c>\widetilde{c}$ : Market Foreclosure}

In this section, we analyze the case in which the MNE's subsidiary is more efficient than the foreign input supplier $(c<\widetilde{c})$ and firm 1 always sets up its subsidiary. In particular, we address the MNE's incentives to supply its input to the domestic final-good competitor, firm 2 .

With the timing assumption we have, the MNE has the following options. If it decides to supply to firm 2, its optimal pricing strategy is to set a price equal to the foreign supplier's MC to prevent undercutting, that is, $\gamma=\widetilde{c}$ because a lower price makes the rival firm more competitive and its own PMC higher. ${ }^{18}$ With this choice, the equilibrium

\footnotetext{
${ }^{18}$ We make the tie-breaking assumption that if firm 2 is indifferent across suppliers, it purchases from the most efficient supplier. This assumption is made without any loss of generality to avoid the open set problem.
} 
outputs of firms 1 and 2 can be written as $q\left(\xi^{C U P}(\widetilde{c}), \widetilde{c}\right)$ and $q\left(\widetilde{c}, \xi^{C U P}(\widetilde{c})\right)$, respectively, where $\xi^{C U P}(\widetilde{c}) \equiv \frac{(1-\widetilde{t}) c-(t-\widetilde{t}) \widetilde{c}}{1-t}$. The corresponding MNE's profit can be written as

$$
\Pi=(1-t) \pi\left(\xi^{C U P}(\widetilde{c}), \widetilde{c}\right)+(1-\widetilde{t})(\widetilde{c}-c) q\left(\widetilde{c}, \xi^{C U P}(\widetilde{c})\right)
$$

If the subsidiary refuses to sell to firm 2 and the foreign input supplier supplies to firm 2 , the foreign input supplier will set a price of $\widetilde{\gamma}^{*}$ (characterized by condition (8) above), and the MNE's profit can be written as

$$
\Pi^{\text {Foreclosure }}=(1-t) \pi\left(\xi^{C U P}\left(\widetilde{\gamma}^{*}\right), \widetilde{\gamma}^{*}\right) .
$$

As is standard in the vertical-integration literature, there are trade-offs between raising rival's costs against loss of the upstream profit when the MNE engages in input foreclosure to the rival downstream firm. In our set-up, it turns out that the effect of raising rival's costs becomes weaker compared to the standard IO model, as will be shown below. However, there is an additional benefit of foreclosure in terms of tax payments because the input foreclosure increases the input price faced by firm 2 from $\widetilde{c}$ to $\widetilde{\gamma}^{*}$ which is used as the benchmark transfer price in the CUP method.

To be more specific, firm 1's subsidiary refuses to sell to firm 2 if $\Pi^{\text {Foreclosure }}>\Pi$. This condition can be decomposed as follows:

$$
\begin{aligned}
& \Pi^{\text {Foreclosure }}-\Pi \\
& =(1-t) \underbrace{\left[\pi\left(\xi^{C U P}\left(\widetilde{\gamma}^{*}\right), \widetilde{\gamma}^{*}\right)-\pi\left(\xi^{C U P}(\widetilde{c}), \widetilde{c}\right)\right]}_{\text {Beneficial Effects of Input Foreclosure }}-(1-\widetilde{t}) \underbrace{(\widetilde{c}-c) q\left(\widetilde{c}, \xi^{C U P}(\widetilde{c})\right)}_{\text {Loss of Upstream Profit }}>(\mathbf{0} 0) \\
& \text { for Downstream Division }
\end{aligned}
$$

Note that the expression for the beneficial effects of input foreclosure for the downstream division can be further decomposed as

$$
\begin{aligned}
{\left[\pi\left(\xi^{C U P}\left(\widetilde{\gamma}^{*}\right), \widetilde{\gamma}^{*}\right)-\pi\left(\xi^{C U P}(\widetilde{c}), \widetilde{c}\right)\right]=} & \underbrace{\left[\pi\left(\xi^{C U P}\left(\widetilde{\gamma}^{*}\right), \widetilde{\gamma}^{*}\right)-\pi\left(\xi^{C U P}(\widetilde{c}), \widetilde{\gamma}^{*}\right)\right]}_{\text {Tax Manipulation Motives }} \\
& +\underbrace{\left[\pi\left(\xi^{C U P}(\widetilde{c}), \widetilde{\gamma}^{*}\right)-\pi\left(\xi^{C U P}(\widetilde{c}), \widetilde{c}\right)\right]}_{\text {Weakened Raising-Rival's-Costs Effects (WRR) }} .
\end{aligned}
$$


The first beneficial effect comes from the fact that a higher input price paid by firm 2 due to market foreclosure leads to a higher transfer price under the CUP method which enables more profit shifting resulting from a lower PMC for the MNE. The second benefit is the standard raising-rival's-cost effect.

However, the raising rival's cost in our set-up is weaker owing to the dependence of firm 1's transfer price on the foreign supplier's price as shown in section 4.1: a lower PMC for the MNE as a result of a higher input price leads to a more aggressive response by firm 1, reducing firm 2's demand for its input. This limits the foreign supplier's incentive to raise the input price. To see this, let $\gamma_{s}^{*}$ denote the MNE's optimal input price if there were no dependence of PMC on its price. Then, $\gamma_{s}^{*}>\widetilde{\gamma}^{*}$ and we can write

$$
\begin{aligned}
W R R \equiv & \underbrace{\left[\pi\left(\xi^{C U P}(\widetilde{c}), \widetilde{\gamma}^{*}\right)-\pi\left(\xi^{C U P}(\widetilde{c}), \widetilde{c}\right)\right]}_{\text {Weakened Raising Rival's Costs Effects }}=\{\underbrace{\left[\pi\left(\xi^{C U P}(\widetilde{c}), \gamma_{s}^{*}\right)-\pi\left(\xi^{C U P}(\widetilde{c}), \widetilde{c}\right)\right]}_{\text {Standard Raising Rival's Costs Effects }} \\
& -\underbrace{\left[\pi\left(\xi^{C U P}(\widetilde{c}), \gamma_{s}^{*}\right)-\pi\left(\xi^{C U P}(\widetilde{c}), \widetilde{\gamma}^{*}\right)\right]}_{\text {Weakening Factor due to Price Dependence }}\} .
\end{aligned}
$$

Taken together, if the two beneficial effects in (11) are larger than the loss of upstream profit, the MNE engages in input foreclosure and commits not to supply to firm 2 even if it is more efficient producer of the input. More precisely, let $\bar{\gamma}$ be the rival firm's inputacquisition cost which will make the MNE indifferent between supplying the rival firm and not supplying, that is,

$$
\Pi=\Pi^{\text {Foreclosure }}(\bar{\gamma})=(1-t) \pi\left(\xi^{C U P}(\bar{\gamma}), \bar{\gamma}\right)
$$

Then, if $\widetilde{\gamma}^{*}>\bar{\gamma}$, the MNE decides not to supply the rival firm even though its production cost is lower than the foreign input supplier.

We thus provide a novel mechanism through which input foreclosure can takes place even in the absence of raising rival's costs. To isolate our mechanism, consider an extreme case in which firm 1 and firm 2 are not direct competitors, which eliminates any incentives to raise rival's costs. We assume symmetric market for both firms and let $q^{m}(c)$ denote the monopoly quantity of each firm when its cost is $c$ and let $\pi^{m}(c)$ be the corresponding monopoly profit in each market. When the two firms are not direct competitors, $\pi^{m}(c)$ is 
independent of the other firm's costs and we have $W R R=0$. Then, (10) becomes

$$
\Pi^{\text {Foreclosure }}-\Pi=(1-t) \underbrace{\left[\pi\left(\xi^{C U P}\left(\widetilde{\gamma}^{*}\right)\right)-\pi\left(\xi^{C U P}(\widetilde{c})\right]\right.}_{\text {Tax Manipulation Motives }}-(1-\widetilde{t}) \underbrace{(\widetilde{c}-c) q^{m}(\widetilde{c})}_{\text {Loss of Upstream Profit }} .
$$

As the loss of upstream profit goes to zero as $\widetilde{c}$ approaches $c$, we have $\Pi^{\text {Foreclosure }}-\left.\Pi\right|_{\tilde{c}=c}>$ 0 . By the continuity argument, we can conclude that the MNE essentially refuses to sell its input to the downstream rival and foreclosure takes place unless the MNE is sufficiently more efficient than the foreign supplier.

For instance, suppose demands for both final goods are given by $P(q)=\theta-q$ and $c=0<\widetilde{c}<\theta$. When the MNE commits not to supply to firm 2 , it can be easily verified that $\widetilde{\gamma}^{*}=\frac{\theta+\widetilde{c}}{2}$ and the loss of MNE's upstream profit from foreclosure is given by $\widetilde{c}\left(\frac{\theta-\widetilde{c}}{2}\right)$ whereas the tax-manipulation-motives term becomes

$$
\pi\left(\xi^{C U P}\left(\widetilde{\gamma}^{*}\right)\right)-\pi\left(\xi^{C U P}(\widetilde{c})\right)=\left(\frac{\theta+\frac{(t-\widetilde{t})}{1-t} \frac{(\theta+\widetilde{c})}{2}}{2}\right)^{2}-\left(\frac{\theta+\frac{(t-\widetilde{t}) \widetilde{c}}{1-t}}{2}\right)^{2}
$$

because $\xi^{C U P}(\widetilde{c})=-\frac{(t-\widetilde{t}) \widetilde{c}}{1-t}$ and $\xi^{C U P}\left(\widetilde{\gamma}^{*}\right)=-\frac{(t-\widetilde{t}) \widetilde{\gamma}^{*}}{1-t}=-\frac{(t-\widetilde{t})}{1-t} \frac{(\theta+\widetilde{c})}{2}$. We can easily confirm that $\Pi^{\text {Foreclosure }}-\left.\Pi\right|_{\tilde{c}=c=0}>0$ and hence $\Pi^{\text {Foreclosure }}-\Pi>0$ for any $\widetilde{c}$ sufficiently close to $c=0$, which results in an inefficient outcome. The MNE's incentive for tax manipulation via transfer price induces the less efficient input supplier to supply the input to firm 2 . In addition, the exercise of market power leads to a higher consumer price in market 2 , meaning an additional welfare loss.

\section{Concluding Remarks}

We have analyzed MNE's incentives to manipulate an internal transfer price to take advantage of tax differences across countries and OECD's ALP to mitigate such incentives under imperfect competition. We specifically focused on the case in which the downstream production and the upstream production are, respectively, done in Home and Foreign and the corporate tax rate is higher in Home than in Foreign. We considered the $\mathrm{CP}$ and the CUP methods as two alternative implementations of the ALP.

We first analyzed the case where the home final-good market is monopolized by a single home firm. We derived the conditions under which it establishes a foreign subsidiary for the purpose of transfer pricing. Such tax-induced FDI could entail inefficient internal 
production but benefits home consumers. The application of the $\mathrm{CP}$ method makes the MNE and consumers worse off and social welfare may deteriorate. With the concealment costs convex in output, dual sourcing may arise under the CP method. If dual sourcing triggers the CUP method instead, then it is possible that the MNE and consumers get hurt and tax revenue decreases.

With oligopolistic competition in the home final-good market, the internal transfer price has additional strategic effects that further strengthen incentives to inflate the transfer price at the expense of rivals' profits. The tax-induced FDI by the MNE has spillover effects that reduce tax revenue from the other home firms as well as the MNE. Furthermore, we uncovered a novel mechanism for input foreclosure when the input market is also imperfectly competitive and the CUP method is applied. The MNE may have incentive for input foreclosure even if is a more efficient input producer. The new mechanism stems from dependence of the transfer price on the market price of a "comparable" input, which is endogenously determined.

We have considered a specific industry in which the MNE is operating. We implicitly assumed that the overall corporate tax rate is determined by factors outside of the model. The overall corporate tax rate thus cannot be tailored for this particular industry and is considered exogenously given. However, in the face of MNE's profit-shifting incentives, the home government may impose industry-specific import tariffs to eliminate such incentives. We have explored import tariffs adopted as countermeasures against profit shifting. In particular, the optimal tariff in general allows some profit shifting due to consumer-surplus considerations (see Corollary 1) even though there exists a tariff level that completely offsets any incentives for profit shifting. Our welfare analysis of the ALP also has important policy implications. We showed that better institutional monitoring and the ALP regulation are complementary. They need to be implemented simultaneously. Imposing the ALP without high-quality monitoring in place can be counter-productive.

Finally, we have analyzed FDI decision of only one firm in isolation in the oligopoly case assuming that the other firms engage in outsourcing. However, each firm's FDI decision may also depend on the other firms' FDI decisions. This is an area of future research. 


\section{References}

[1] Alles, M., Datar, S., 1998. Strategic transfer pricing. Management Science 44, 451461.

[2] Allingham, M. G., Sandmo, A., 1972. Income tax evasion: a theoretical analysis. Journal of Public Economics, 323-338.

[3] Arya, A, Mittendorf, B., 2008. Pricing internal trade to get a leg up on external rivals. Journal of Economics and Management Strategy 17, 709-731.

[4] Batra, R. N., Hadar, J., 1979. Theory of the multinational firm: fixed versus floating exchange rates. Oxford Economic Papers 31, 258-69.

[5] Bauer, C. J., Langenmayr, D., 2013. Sorting into outsourcing: Are profits taxed at a gorilla's arm's length? Journal of International Economics 90, 326-336.

[6] Bernard, A. B., Jensen, J. B., Redding, S.J., Schott, P.K., 2010. Intrafirm trade and product contractibility. American Economic Review 100, 444-448.

[7] Bond, E. W., 1980. Optimal transfer pricing when tax rates differ. Southern Economic Journal 47, 191-200.

[8] Bulow, J. I., Pfleiderer, P., 1983. A note on the effect of cost changes on prices. Journal of Political Economy 91, 182-185.

[9] Clausing, K. A., 2003. Tax-motivated transfer pricing and US intrafirm trade prices. Journal of Public Economics 87, 2207-2223.

[10] Copithorne, L.W., 1971. Internal corporate transfer prices and government policy. Canadian Journal of Economics 4, 324-341.

[11] Davies, R., Martin, J., Parenti, M., Toubal, F., 2016. Knocking on tax haven's door: multinational firms and transfer pricing, CEPR Discussion Paper No. 10844.

[12] Egger, P., Eggert, W., Winner, H., 2010. Saving taxes through foreign plant ownership. Journal of International Economics 81, 99-108.

[13] Egger, P., Seidel, T., 2013. Corporate Taxes and Intra-Firm Trade, European Economic Review 63, 225-242. 
[14] Gresik, T., Osmundsen, P., 2008. Transfer pricing in vertically integrated industries. International Tax and Public Finance 15, 231-255.

[15] Haufler, A., Schjelderup,G., 2000. Corporate tax systems and cross country profit shifting. Oxford Economic Papers 52, 306-325.

[16] Hines, J., RICE. E., 1994. Fiscal paradise: foreign tax havens and American business. Quarterly Journal of Economics 109, 149-81.

[17] Hirshleifer, J., 1956. On the economics of transfer pricing. Journal of Business, $172-$ 184.

[18] Horst,. T., 1971. The theory of the multinational firm: optimal behavior under different tariff and tax rates. Journal of Political Economy 79, 1059-1072.

[19] Huizinga, H., Laeven, L., 2008, International profit shifting within multinationals: A multi-country perspective. Journal of Public Economics 92, 1164-1182.

[20] Itagaki, T., 1979. Theory of the multinational firm: an analysis of effect of government policies. International Economic Review 10, 437-448

[21] Itagaki, T., 1981. The theory of the multinational firm under exchange rate uncertainty. Canadian Journal of Economics 14, 276-297.

[22] Kant, C., 1988. Endogenous transfer pricing and the effects of uncertain regulation, Journal of International Economics 24, 147-157.

[23] Kato, H., Okoshi, H., 2017. Production location of multinational firms under transfer pricing: the impact of arm's length principle, unpublished manuscript.

[24] Nielsen, S. B. , Raimondos-Moller, P. and Schjelderup, G., 2008. Taxes and decision rights in multinationals. Journal of Public Economic Theory 10, 245-258.

[25] OECD, 2010, OECD Transfer Pricing Guidelines for Multinational Enterprises and Tax Administrations 2010, OECD Publishing, Paris. DOI: http://dx.doi.org/10.1787/tpg-2010-en.

[26] Ordover, J. A., Saloner, G., Salop, S. C., 1990. Equilibrium vertical foreclosure. American Economic Review 80, 127-142. 
[27] Ordover, J. A., Saloner, G., Salop, S. C., 1992. Equilibrium vertical foreclosure: reply. American Economic Review 82, 698-703.

[28] Reiffen, D., 1992. Equilibrium vertical foreclosure: comment. American Economic Review 82, 694-697.

[29] Salop, S. C. and David T. S., 1983. Raising rivals' costs. American Economic Review $73,267-271$.

[30] Samuelson, L. 1982. The multinational firm with arm's length transfer price limits. Journal of International Economics 13, 365-374.

[31] Schjelderup G. and Sorgard, L., 1997. Transfer pricing as a strategic device for decentralized multinationals. International Tax and Public Finance 4, 277-290.

[32] Weyl, E. G., Fabinger, M. 2013. Pass-through as an economic tool: principles of incidence under imperfect competition. Journal of Political Economy 121, 528-583. 


\section{Appendix}

\section{Social Welfare Analysis of the ALP when the Concealment Cost is the Expected Fine:}

Welfare under the ALP is higher if the concealment cost is not a wasteful activity (as analyzed in section 2.5), but is the expected penalty that is a pure transfer which goes from the MNE to the government. The expected penalty, $\phi(\gamma-c) q$, can be interpreted as the probability that the MNE is caught, $\phi(\gamma-c) / \alpha$ times the fine, $F=\alpha q$, for some $\alpha>0$. Or it can be interpreted as the exogenous probability of being caught, $p$, times the fine $\phi(\gamma-c) q / p$. In any event, the MNE, faced with the concealment cost of $\phi(\gamma-c) q$ behaves exactly the same as under the ALP with the real concealment costs. In particular, it chooses $\gamma^{*}=c+\frac{t-\tilde{t}}{k}$, and hence the perceived marginal cost equals $\xi\left(\gamma^{*}\right)$. But the social planner's perceived marginal cost is different from the previous case, because the penalty is a mere transfer from the MNE to the government. Noting that the penalty does not enter the social planner's perceived marginal cost, we can write the social welfare in this case as

$$
W^{P}=\int_{0}^{q\left(\xi\left(\gamma^{*}\right)\right)} P(q) d q-\xi^{N R S P}\left(\gamma^{*}\right) q\left(\xi\left(\gamma^{*}\right)\right)
$$

where

$$
\xi^{N R S P}\left(\gamma^{*}\right)=(1-t) \xi^{N R}\left(\gamma^{*}\right)+t \gamma^{*}=c+\tilde{t}\left(\gamma^{*}-c\right)=c+\frac{\tilde{t}(t-\tilde{t})}{k} .
$$

Unlike the welfare comparison in section 2.5, we have a clear trade-off in this case. The ALP increases the MNE's perceived marginal cost, i.e., $\xi^{N R}\left(\gamma_{0}^{*}\right)<\xi\left(\gamma^{*}\right)$, and hence reducing the production, while it lower's the social planner's perceived marginal cost, i.e., $\xi^{N R S P}\left(\gamma_{0}^{*}\right)>\xi^{N R S P}\left(\gamma^{*}\right)$. Despite the fact that social welfare under the ALP in this case is higher than that in the case of the real concealment cost, we obtain qualitatively the same numerical result that the ALP does reduces social welfare if $t$ is large or $\tilde{t}$ is small.

Although the ALP limits the MNE's incentive to choose inefficient production location for the sake of saving the corporate tax, it would induce the MNE to produce less and hence could lead to the deterioration of social welfare. This basic message regarding the welfare impact of the ALP will also be valid in a duopoly case that we examine in the next section.

\section{Proof of Proposition 6:}

By Lemma 3, we know $\widehat{\xi}^{*}-\widehat{\xi}^{S P} \geq 0$ for all $\tau_{m} \geq \tau_{m}^{o}$. As in the proof of Proposition 
2 , for all $\tau_{m} \geq \tau_{m}^{o}$, we thus have

$$
\begin{aligned}
\frac{d W}{d \tau_{m}} & <-P^{\prime} q \frac{d q\left(\tau_{m}\right)}{d \tau_{m}}-q\left(\tau_{m}\right) \frac{d \widehat{d \xi}^{S P}}{d \tau_{m}} \\
& =-q\left[P^{\prime} \frac{d q}{d \xi} \frac{d \xi}{d \tau_{m}}+\frac{d \widehat{\xi}^{S P}}{d \tau_{m}}\right]
\end{aligned}
$$

A sufficient condition for $\frac{d W}{d \tau_{m}}<0$ to be true for all $\tau_{m} \geq \tau_{m}^{o}$ is $\rho>\frac{\left|\frac{d \widehat{\xi}^{S P}}{d \tau_{m}}\right|}{\frac{d \xi}{d \tau_{m}}}=\frac{\left|\frac{d \widehat{\xi}^{S P}}{d \tau_{m}}\right|}{\widehat{\gamma}^{*}}<0$.

When $\phi$ is quadratic with $\phi^{\prime \prime \prime}=0$, it can be easily verified that

$$
\frac{d \frac{d \frac{d \widehat{\xi}^{S P}}{d \tau_{m}} \mid}{\frac{d \xi}{d \tau_{m}}}}{d \tau_{m}}=\frac{(1-t)}{\left(\widehat{\gamma}^{*}\right)^{2}}\left[\widehat{\gamma}^{*}+\frac{\widetilde{t}+\phi^{\prime}}{\phi^{\prime \prime}}\right] \underbrace{\frac{d \widehat{\gamma}^{*}}{d \tau_{m}}}_{(-)}<0 .
$$

Thus, if $\rho>\left.\frac{\left|\frac{d \widehat{\xi}^{S P}}{d \tau_{m}}\right|}{\frac{d \xi}{d \tau_{m}}}\right|_{\tau_{m}=\tau_{m}^{o}}$, the sufficient condition is satisfied for all $\tau_{m} \geq \tau_{m}^{o}$.

\section{Proof of Lemma 3:}

Totally differentiating the two FOCs (6) and (7), we have

$$
\begin{aligned}
\frac{\partial^{2} \pi_{1}\left(q_{1}, q_{2} ; \xi\right)}{\partial q_{1}^{2}} d q_{1}+\frac{\partial^{2} \pi_{1}\left(q_{1}, q_{2} ; \xi\right)}{\partial q_{1} \partial q_{2}} d q_{2}+\frac{\partial^{2} \pi_{1}\left(q_{1}, q_{2} ; \xi\right)}{\partial q_{1} \partial \xi} d \xi & =0 \\
\frac{\partial^{2} \pi_{2}\left(q_{1}, q_{2}\right)}{\partial q_{1} \partial q_{2}} d q_{1}+\frac{\partial^{2} \pi_{2}\left(q_{1}, q\right)}{\partial q_{2}^{2}} d q_{2}+0 \cdot d \xi & =0 .
\end{aligned}
$$

To conduct a comparative static analysis on $\xi$, we can rewrite the equations above as

$$
\left[\begin{array}{cc}
\frac{\partial^{2} \pi_{1}\left(q_{1}, q_{2} ; \xi\right)}{\partial q_{1}^{2}} & \frac{\partial^{2} \pi_{1}\left(q_{1}, q_{2} ; \xi\right)}{\partial q_{1} \partial q_{2}} \\
\frac{\partial^{2} \pi_{2}\left(q_{1}, q_{2}\right)}{\partial q_{1} \partial q_{2}} & \frac{\partial^{2} \pi_{2}\left(q_{1}, q\right)}{\partial q_{2}^{2}}
\end{array}\right]\left[\begin{array}{c}
\frac{d q_{1}}{d \xi} \\
\frac{d q_{2}}{d \xi}
\end{array}\right]=-\left[\begin{array}{c}
\frac{\partial^{2} \pi_{1}\left(q_{1}, q_{2} ; \xi\right)}{\partial q_{1} \partial \xi} \\
0
\end{array}\right] .
$$

Note that $\frac{\partial \pi_{1}\left(q_{1}, q_{2} ; \xi\right)}{\partial \xi}=-q_{1}$ by the envelope theorem and hence $\frac{\partial^{2} \pi_{1}\left(q_{1}, q_{2} ; \xi\right)}{\partial q_{1} \partial \xi}=-1$. Applying 
the Cramer's rule, we obtain

$$
\begin{aligned}
& \frac{d q_{1}}{d \xi}=\frac{\left|\begin{array}{cc}
1 & \frac{\partial^{2} \pi_{1}\left(q_{1}, q_{2} ; \gamma\right)}{\partial q_{1} \partial} \\
0 & \frac{\partial^{2} \pi_{2}\left(q_{1}, q\right)}{\partial q_{2}^{2}}
\end{array}\right|}{D}=\frac{\frac{\partial^{2} \pi_{2}\left(q_{1}, q_{2}\right)}{\partial q_{2}^{2}}}{D}<0, \\
& \frac{d q_{2}}{d \xi}=\frac{\left|\begin{array}{cc}
\frac{\partial^{2} \pi_{1}\left(q_{1}, q_{2} ; \gamma\right)}{\partial q_{1}^{2}} & 1 \\
\frac{\partial^{2} \pi_{2}\left(q_{1}, q_{2}\right)}{\partial q_{1} \partial q_{2}} & 0
\end{array}\right|}{D}=-\frac{\frac{\partial^{2} \pi_{2}\left(q_{1}, q_{2}\right)}{\partial q_{1} \partial q_{2}}}{D}>0,
\end{aligned}
$$

where $D \equiv\left[\frac{\partial^{2} \pi_{1}\left(q_{1}, q_{2} ; \gamma\right)}{\partial q_{1}^{2}} \frac{\partial^{2} \pi_{2}\left(q_{1}, q\right)}{\partial q_{2}^{2}}-\frac{\partial^{2} \pi_{1}\left(q_{1}, q_{2} ; \gamma\right)}{\partial q_{1} \partial q_{2}} \frac{\partial^{2} \pi_{2}\left(q_{1}, q_{2}\right)}{\partial q_{1} \partial q_{2}}\right]>0$. We obtain the desired result, because we have $\frac{\partial^{2} \pi_{2}\left(q_{1}, q_{2}\right)}{\partial q_{2}^{2}}<0$ by the second-order condition and $\frac{\partial^{2} \pi_{2}\left(q_{1}, q_{2}\right)}{\partial q_{1} \partial q_{2}}<0$ by the assumption of strategic substitutes. 